\title{
Isothermal and Non-isothermal Crystallization Kinetics of Mold Fluxes used in Continuous Casting of Steel: A Review
}

\begin{abstract}
RAHUL SARKAR and ZUSHU LI
Casting powders or mold fluxes, as they are more commonly known, are used in the continuous casting of steel to prevent the steel shell from sticking to the copper mold. The powders first melt and create a pool of liquid flux above the liquid steel in the mold, and then the liquid mold fluxes penetrate into the gap between water-cooled copper mold and steel shell, where crystallization of solid phases takes place as the temperatures gradually drop. It is important to understand the crystallization behavior of these mold fluxes used in the continuous casting of steel because the crystalline phase fraction in the slag films plays a crucial role in determining the horizontal heat flux during the casting process. In this work, the existing literature on the crystallization kinetics of conventional and fluoride-free mold fluxes used in the continuous casting of steel has been reviewed. The review has been divided into two main sections viz. the isothermal crystallization kinetics and non-isothermal crystallization kinetics. Under each of these sections, three of the most widely used techniques for studying the crystallization kinetics have been included viz. thermoanalytical techniques such as differential scanning calorimetry/differential thermal analysis (DSC/DTA), the single and double hot thermocouple technique (SHTT and DHTT), and the confocal scanning laser microscopy (CSLM). For each of these techniques, the available literature related to the crystallization kinetics of mold fluxes has been summarized thereby encompassing a wide range of investigations comprising of both conventional and fluoride-free fluxes. Summaries have been included after each section with critical comments and insights by the authors. Finally, the relative merits and demerits of these methods vis-à-vis their application in studying the crystallization kinetics of mold fluxes have been discussed.
\end{abstract}

https://doi.org/10.1007/s11663-021-02099-5

(C) The Author(s) 2021

\section{INTRODUCTION}

IN the continuous casting process of steel, molten steel is poured from the ladle through a submerged entry nozzle (SEN) into the tundish, which maintains a constant head for molten steel to flow into the continuous casting mold. ${ }^{[1]}$ As the molten steel passes through the mold, it freezes against the cold walls of the mold and forms a shell of solidified steel. The steel shell will have a tendency to stick to the mold unless measures are taken to prevent it. One of the most important measures that are taken to prevent the sticking of the shell to the mold is the use of casting powders. ${ }^{[1-4]}$ These powders are fed at the top of the mold where they are gradually heated up and create a pool of liquid flux. A significant

RAHUL SARKAR and ZUSHU LI are with the Advanced Steel Research Center, WMG, University of Warwick, Coventry CV4 7AL, UK. Contact e-mail: rahulsarkar.jumet@gmail.com

Manuscript submitted August 16, 2020; accepted January 28, 2021. Article published online April 2, 2021. amount of this molten flux enters the gap between the mold and the steel shell and freezes against the cold to form a solid slag thereby leaving behind a thin liquid film against the shell. The liquid film maintains the lubrication of the shell and while the solid slag film is responsible for maintaining the horizontal heat flux $\left(q_{h o r}\right) .^{[5]}$ A schematic representation of the various phases and their location in the mold is shown in Figure $1 .^{[1]}$

The initial slag film formed is primarily glassy because of the high cooling rates at which it is quenched against the cold mold wall but over time, the fraction of crystallized phases in the slag film increases until a steady-state value is reached. Therefore, after sufficiently long times, the slag film consists of a combination of a glassy phase and crystalline phases. The crystalline phases reflect and scatter radiant energy that leaves the steel shell and therefore $q_{h o r}$ decreases with increasing amount of crystalline phases in the slag film. Also, crystalline phases inherently have higher densities as compared to the glassy phase and therefore the formation of crystalline phases is associated with a shrinkage 
which results in the formation of porosity in the slag film and also an interfacial thermal resistance $\left(R_{C u / s l}\right)$ associated with "air or gas gap.",[6-10]

As already mentioned, since this slag film is primarily responsible for maintaining the horizontal heat transfer between the mold and the steel shell, the horizontal heat flux can then be expressed as

$$
q_{\text {hor }}=\frac{\Delta T}{R_{e f f}},
$$

where $q_{h o r}$ is the horizontal heat flux, $\Delta T$ is the temperature difference, and $R_{\text {eff }}$ is the effective heat transfer resistance given by

$$
R_{\text {eff }}=R_{C u / s l}+R_{g l}+R_{\text {crys }}+R_{\text {liq }} .
$$

It is evident from Eqs. [1] and [2] and also from the preceding discussion that the crystalline phase fraction $\left(f_{\text {crys }}\right)$ has an important role in the horizontal heat transfer and therefore it is important to determine $f_{\text {crys }}$ of slag films. There are several methods to determine $f_{\text {crys }}$ of slag films using conventional techniques such as optical microscopy (OM), X-ray diffraction (XRD), and thermoanalytical techniques such as DSC. ${ }^{[11-13]}$ Using these techniques, the $f_{\text {crys }}$ in slag films can be determined as a function of the chemical composition of the mold fluxes and also as a function of position in the continuous casting mold. The $f_{\text {crys }}$ values obtained from these techniques, however, are all steady-state values and information about how the $f_{\text {crys }}$ evolves as a function of time cannot be obtained from these techniques. But as discussed, the $f_{\text {crys }}$ in the slag film is a function of both temperature and time and it is of fundamental interest how the $f_{\text {crys }}$ changes as functions of these two parameters.

The crystallization kinetics of mold slags used in continuous casting of steel is essentially related to how the crystalline phase fraction $\left(f_{\text {crys }}\right)$ changes as a function of both time and temperature and plays a critical role in the optimization of heat transfer and lubrication in the continuous casting mold. Therefore, the crystallization kinetics of mold fluxes of different compositions has been extensively studied in the literature using a variety of techniques. In addition, there are several studies on the thermophysical properties such as viscosity, liquidus and glass transition temperature, surface and interfacial tension, thermal conductivity, density, and heat capacity since these properties also play an important role in the crystallization phenomena. ${ }^{[14-19]}$ In the recent past, a special emphasis has been laid on the design of mold fluxes for casting innovative grades such as high-Al TRIP and TWIP steels. ${ }^{[1]}$ In these steel grades, the Al in the steel tends to react with $\mathrm{SiO}_{2}$ in the mold slag to produce $\mathrm{Al}_{2} \mathrm{O}_{3}$. As a result, the $\mathrm{Al}_{2} \mathrm{O}_{3}$ content in the slag increases and consequently the break temperature and $f_{\text {crys }}$ increase significantly. This often results in an erratic melting behavior, fluctuations in the mold temperatures, and false alarms on the sticker detection systems. In addition, it has been contended that for steel containing $>1$ wt pet $\mathrm{Al}$, the presence of high $\mathrm{Al}_{2} \mathrm{O}_{3}$ in the mold

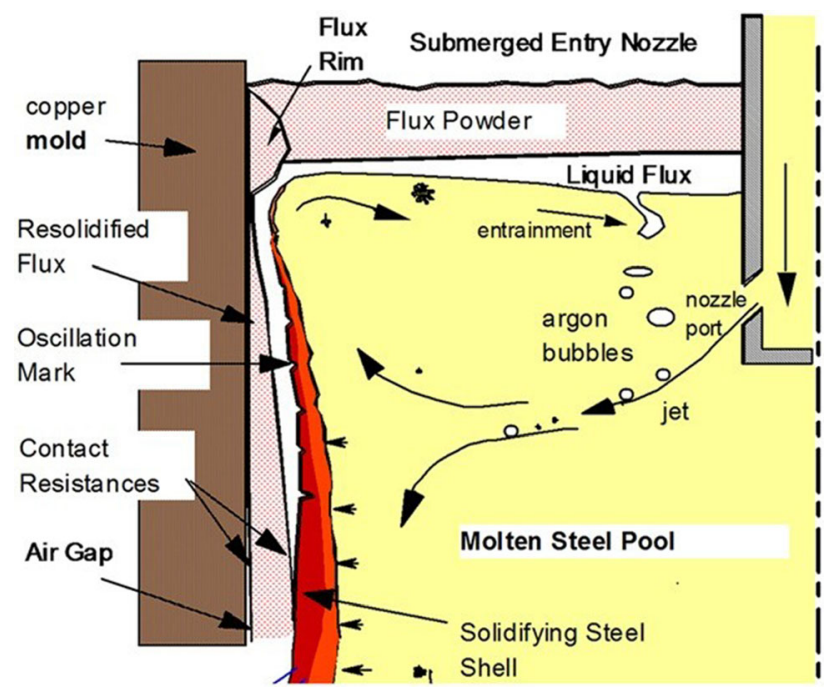

Fig. 1-Schematic representation of the various phases and their locations in the mold used for continuous casting of steel (reproduced with permission from Ref. [1]).

slag promotes crystallization at the expense of the glassy phase thus resulting in a loss in lubrication. Therefore, significant efforts have been made in the past few years to modify the conventional $\mathrm{CaO}-\mathrm{SiO}_{2}$-based mold fluxes and to develop new fluxes based on the $\mathrm{CaO}-\mathrm{Al}_{2} \mathrm{O}_{3}$ system (with considerably lower amounts of $\mathrm{SiO}_{2}$ ) for casting high-Al steel. The use of these new fluxes minimizes the amount of $\mathrm{Al}_{2} \mathrm{O}_{3}$ formed as a result of the reaction between $\mathrm{Al}$ in steel and $\mathrm{SiO}_{2}$ in the mold slag. ${ }^{[1]}$ However, with the use of these new $\mathrm{CaO}-\mathrm{Al}_{2} \mathrm{O}_{3}-$ based fluxes, there is a significant change in the composition of the crystalline phases and in a recent study, Zhou et al. ${ }^{[20]}$ reported that the precipitated phases change from cuspidine $\left(\mathrm{Ca}_{4} \mathrm{Si}_{2} \mathrm{O}_{7} \mathrm{~F}_{2}\right)$ to nepheline $\left(\mathrm{NaAlSiO}_{4}\right)$ and $\mathrm{CaF}_{2}$, and then into gehlenite $\left(\mathrm{Ca}_{2} \mathrm{Al}_{2} \mathrm{SiO}_{7}\right)$ as the alumina content increases from 7 to $40 \mathrm{wt}$ pct. The impact of these newer crystalline phases on the overall crystallization process is not fully understood and is an area of active research. Similar approaches have also been followed for other challenging grades such as the Ti-stabilized peritectic stainless steel wherein $\mathrm{SiO}_{2}$ in the mold flux is replaced by $\mathrm{TiO}_{2}$ (for up to $10 \mathrm{wt}$. pet $\mathrm{TiO}_{2}$ ). ${ }^{[1]}$ Another interesting topic that has come up in the recent years is the development of F-free and F-reduced powders. For F-free fluxes, the main problem lies in the replacement of cuspidine $\left(\mathrm{Ca}_{4} \mathrm{Si}_{2} \mathrm{O}_{7} \mathrm{~F}_{2}\right)$ which is the primary crystalline phase in conventional mold fluxes containing fluorine. Two principal candidates that have been suggested are perovskite $\left(\mathrm{CaTiO}_{3}\right)$ and melilite $\left((\mathrm{Ca}, \underline{\mathrm{Na}})_{2}(\underline{\mathrm{Al}}, \underline{\mathrm{Mg}}\right.$, $\left.\underline{\mathrm{Fe}}^{2+}\right)\left[\left(\underline{\mathrm{Al}}, \underline{\mathrm{Si}} \underline{\mathrm{SiO}}_{7}\right]\right)$. However, further investigations need to be done on the suitability of these phases as replacements for cuspidine since the presence of these phases is reported to create problems such as sticker breaker-out in the continuous casting process. ${ }^{[1]}$ Thus, crystallization behavior of mold slags remains, until date, an active area of research in the continuous casting community. As will be discussed later, there are some reviews available in the literature on the individual 
techniques used for studying crystallization kinetics of mold fluxes but to the best of the authors' knowledge, a comprehensive review encompassing all the different techniques is not available. This article presents an extensive overview of the existing literature on the crystallization kinetics of mold fluxes using all the major techniques and will serve as a useful reference for all future investigations on this and related topics.

As with any reaction or transformation, the kinetics of crystallization in mold fluxes can be studied using isothermal and non-isothermal methods. For the sake of brevity, the general principles involved in the analyses of isothermal and non-isothermal reaction kinetics are not discussed here and interested readers are referred to some of the relevant articles on these topics. ${ }^{[21-26]}$ This article only focusses on the studies relevant to mold flux crystallization and is broadly divided into two sections-viz. the isothermal crystallization kinetics and non-isothermal crystallization kinetics.

\section{ISOTHERMAL CRYSTALLIZATION KINET- ICS OF MOLD FLUXES}

Isothermal kinetics, as the name suggests, involve the study of the fraction transformed in a reaction as a function of time at a particular temperature. The investigations on isothermal crystallization kinetics of mold fluxes, therefore, involve rapid cooling of the molten flux to a temperature below the melting point and holding it isothermally at that temperature. The crystallization kinetics are then observed in terms of the fraction transformed as a function of time and the time-temperature-transformation (TTT) diagrams are often constructed. Figure 2 shows a schematic representation of the thermal cycle that is used in the experiments related to isothermal crystallization kinetics of mold fluxes.

Several researchers have studied the isothermal crystallization kinetics using different techniques. These techniques be classified into three categories viz. thermoanalytical techniques such as differential scanning calorimetry/differential thermal analysis (DSC/DTA), the single and double hot thermocouple technique

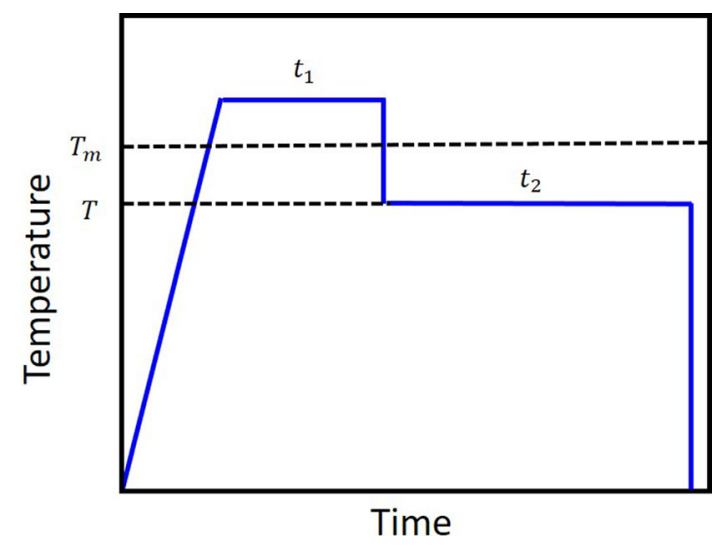

Fig. 2-Schematic of a typical thermal cycle used for isothermal crystallization experiments.
(SHTT and DHTT), and the confocal scanning laser microscopy (CSLM). In the following sections, the available studies on isothermal crystallization kinetics based on these three different techniques have been summarized.

\section{A. Thermoanalytical Techniques}

DSC and DTA are the two most common thermoanalytical techniques used in the analyses of reaction kinetics. In DSC, the sample and the reference material are maintained at the same temperature throughout the controlled temperature program. Any energy difference in the independent supplies to the sample and the reference is then recorded as a function of temperature. On the other hand, in the DTA, the difference in temperature between the sample and the reference is recorded while both are subjected to the same heating program. Both DSC and DTA have almost the same applications in usage and analysis, but DTA is suited more for the determination of characteristic temperatures, while DSC is better suited for the determination of calorific values such as enthalpy of fusion or crystallization. In addition, traditionally, DTA is more of a qualitative method although, if properly calibrated, DTA can also be used for quite accurate quantitative measurements. Generally, the case sensitivity of DTA strongly depends on experimental conditions and therefore calibration for the DTA should be done under the conditions that are as close as possible to ones for the actual experiments.

Both DSC and DTA have been extensively used in the study of isothermal and non-isothermal crystallization kinetics of mold fluxes. In this section, the available studies on isothermal crystallization kinetics using the DSC/DTA are reviewed and the studies under non-isothermal conditions have been reviewed in a subsequent section.

$\mathrm{SeO}$ et al..$^{[27]}$ studied the isothermal melt crystallization in $\mathrm{CaO}-\mathrm{SiO}_{2}-\mathrm{CaF}_{2}$-based mold fluxes using DSC. The mold fluxes studied by these authors had a basicity in the range 0.94 to 1.34 and a fluorine content of 7 to 7.6 pct. Their experimental technique involved melting of the mold flux by heating it to a temperature above $1300{ }^{\circ} \mathrm{C}$ and then cooling the slag at $20^{\circ} \mathrm{C} \mathrm{min}{ }^{-1}$ to the isothermal temperature followed by holding at that temperature for $\sim 120$ minutes. The isothermal holding temperature was varied from 1140 ${ }^{\circ} \mathrm{C}$ to $1160{ }^{\circ} \mathrm{C}$. They reported that cuspidine $(3 \mathrm{CaO} \cdot 2-$ $\mathrm{SiO}_{2} \cdot \mathrm{CaF}_{2}$ ) was the only phase to have crystallized in these mold fluxes and this corresponded to an exothermic peak in the DSC curves. The crystallized phase fraction of cuspidine was calculated based on the assumption that the rate of heat release is proportional to the rate of crystallization, as shown in Figure 3. Therefore, the fraction crystallized $(X)$ was calculated using the formula

$$
X=\frac{\Delta H_{t}}{\Delta H_{t o t}}=\frac{\int_{0}^{t}\left(d H_{c} / d t\right) d t}{\int_{0}^{\infty}\left(d H_{c} / d t\right) d t} .
$$


They applied the well-known Johnson-Mehl-Avrami-Kolmogorov (JMAK) equation to study the isothermal kinetics of melt crystallization, which can be expressed as ${ }^{[27]}$

$$
X=1-\exp \left[-(K t)^{n}\right] .
$$

Seo et al. ${ }^{[27]}$ obtained values of the Avrami exponent in the range $\sim 3$ to 3.4. Thereafter, they concluded that crystallization of cuspidine is controlled by 3-dimensional growth and instantaneous nucleation in the case of large undercooling while for small undercooling, the growth is still 3-dimensional but the nucleation mode is continuous. Another important result from their investigation was the fact that for each of the two mold fluxes studied, the determined effective activation energy for the crystallization process was found to be negative. The authors explained this result by contending that melt crystallization rate was controlled by the free energy change associated with the degree of undercooling. Their explanation, however, was based on a classical theory for homogenous nucleation but in the actual scenario, nucleation can take place heterogeneously at preferential sites such as the mold walls. Therefore, the assumptions inherent to the homogenous nucleation theory may not hold true in reality.

Maldonado et al. ${ }^{[28]}$ also used the DSC technique to study the isothermal crystallization kinetics of $\mathrm{CaO}$ $\mathrm{SiO}_{2}-\mathrm{CaF}_{2}$-based mold fluxes and calculated the TTT diagrams using a novel approach. Two different mold fluxes were used in their study having different basicities and $\mathrm{CaF}_{2}$ concentrations. The approach followed by these authors is briefly described as follows:

For isothermal kinetics, the rate of crystallization can be expressed as a function of the fraction crystallized $X$, as $^{[21]}$

$$
\frac{d X}{d t}=k \cdot f(X)
$$

where $k$ is the reaction rate constant.

Several algebraic equations are available for $f(X)$ but the one proposed by Kissinger ${ }^{[29]}$ is commonly used for crystallization and this is given by ${ }^{[29]}$

$$
f(X)=(1-X)^{r} .
$$

Using Eq. [6] and assuming an Arrhenius behavior for the rate constant $k$, Eq. [5] can be integrated within limits for an isothermal process as ${ }^{[28]}$

$$
\int_{0}^{X} \frac{d X}{(1-X)^{r}}=A e^{-E / R T} \cdot \int_{t_{i}}^{t} d t
$$

The integration in Eq. [7] gives

$$
t=t_{i}+\left(\frac{1-(1-X)^{r}}{A e^{-\frac{E}{R T}}}\right) \cdot\left(\frac{1}{1-r}\right) \text {. }
$$

Equation [8] gives the time required to achieve a certain degree of crystallization $X$, at any time $t$. However, this requires calculation of the parameters $t_{i}$, $A, E$, and $r$. Maldonado et al. ${ }^{[28]}$ calculated these parameters, however, by the non-isothermal

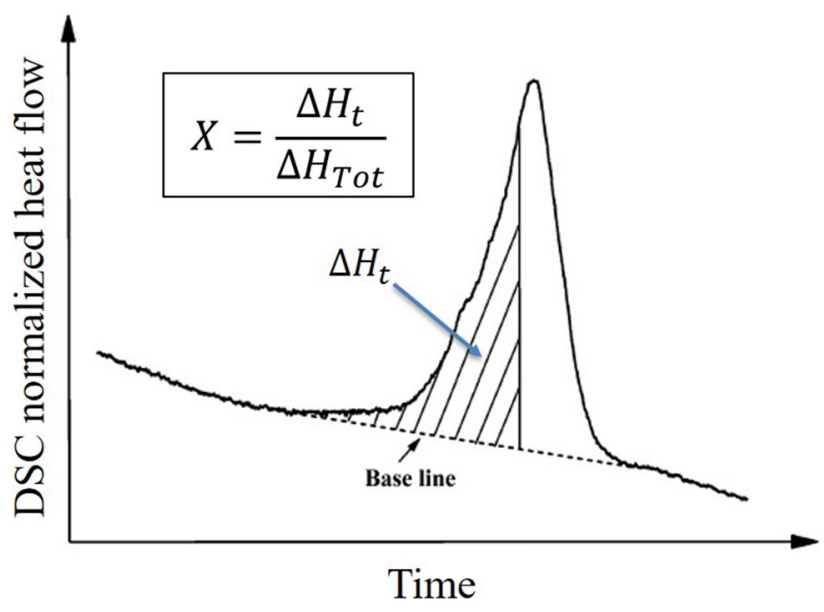

Fig. 3-Schematic representation of the method commonly used for determining fraction transformed $(X)$ as a function of time $(t)$ from DSC traces ${ }^{[27]}$ (reproduced with permission from Ref. [27]).

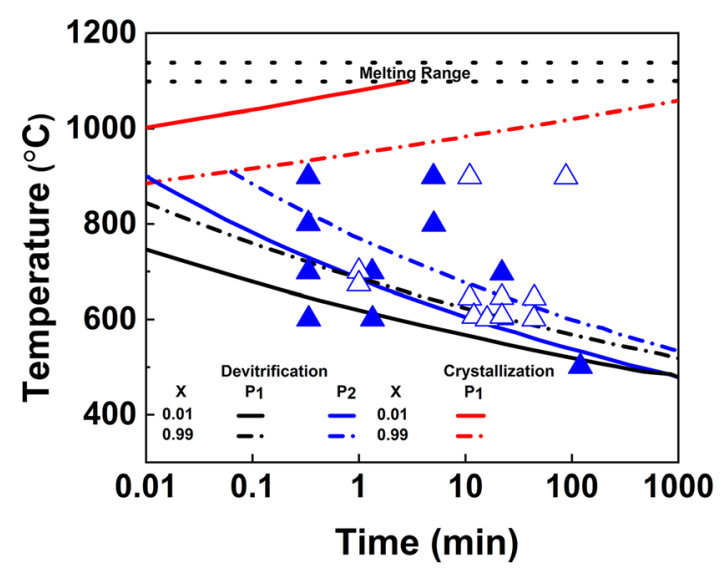

Fig. 4-TTT diagram of a $\mathrm{CaO}-\mathrm{SiO}_{2}-\mathrm{CaF}_{2}$-based mold flux determined using DSC by Maldonando et al. ${ }^{[28]}: \mathrm{P}_{1}$ is Cuspidine $\left(\mathrm{Cu}_{4} \mathrm{Si}_{2} \mathrm{O}_{7} \mathrm{~F}_{2}\right)$ denoted by solid triangles and $\mathrm{P}_{2}$ is Combeite $\left(\mathrm{Na}_{2} \mathrm{Ca}_{2} \mathrm{Si}_{3} \mathrm{O}_{9}\right)$ denoted by closed triangles (reproduced with permission from Maldonado et al. ${ }^{[28]}$ ).

crystallization data obtained at various heating and cooling rates. First, the Induction Period method proposed by Simon ${ }^{[30]}$ was used to determine $t_{i}$ as a function of temperature by using the equation

$$
t_{i}=A^{\prime} e^{\prime B / T_{0}} \text {. }
$$

The other constants in Eq. [8] were then obtained by using the Kissinger plots, ${ }^{[29]}$ which is given by the following equation:

$$
\ln \frac{\beta}{T_{p}^{2}}=\ln \left(\frac{A R r}{E} \cdot\left(1-X_{p}\right)^{r-1}\right)-\frac{E}{R T_{p}},
$$

where $T_{p}$ is the crystallization peak temperature and $X_{p}$ is the fraction crystallized at $T_{p}$. Therefore, in a novel approach, Maldonado et al. ${ }^{[28]}$ used the data obtained from non-isothermal crystallization kinetics to construct the TTT curves, which provide 
information about the isothermal crystallization kinetics. Figure 4 shows an example of the TTT diagram obtained by Maldonado et al. ${ }^{[28]}$ using this novel method.

To validate this new DSC-based technique for TTT diagrams, Maldonado et al. ${ }^{[28]}$ conducted isothermal experiments in which mold slag samples were quenched to the isothermal temperature and then held at that temperature for specified periods of time followed by quenching to room temperatures. Good agreement between these two confirmed the reliability of this method, which can suitably be applied to investigations related to other mold fluxes as well. In a later study, Barraza et al., ${ }^{[31]}$ used the same method to construct the TTT diagrams for mold fluxes used in the high-speed continuous casting of medium carbon steel billets and they too reported that the crystalline phase fractions calculated from the TTT diagrams agreed well with those obtained using the quantitative X-ray phase diffraction analysis (QXRPDA).

Although the thermoanalytical techniques are more commonly used in the study of non-isothermal crystallization kinetics, there are some studies available in the literature on the isothermal crystallization kinetics of mold fluxes using DSC/DTA. In the preceding section, these investigations have been reviewed. Generally speaking, such studies provide important information on the crystallization phenomena taking place at small degrees of undercooling, i.e., at temperatures just below the melting temperature because in such cases it can be appropriately assumed that during the cooling of the mold fluxes from a temperature above the melting temperature to the isothermal holding temperature, little or no crystallization takes place. The well-known JMAK equation can then be applied to the crystallization processes, which occur as a result of isothermal holding at the temperature of interest. As discussed, $\mathrm{SeO}$ et al. ${ }^{[2]}$ have used this approach for studying isothermal melt crystallization of cuspidine $\left(3 \mathrm{CaO} \cdot 2 \mathrm{SiO}_{2} \cdot \mathrm{CaF}_{2}\right)$ in $\mathrm{CaO}-\mathrm{SiO}_{2}-\mathrm{CaF}_{2}$-based mold fluxes. Evidently, this approach of studying isothermal crystallization kinetics using DSC-DTA cannot be applied for large degrees of undercooling and hence the crystallization of phases, which occur at lower temperatures, cannot be studied using this approach. To overcome this limitation, Maldonado et al. ${ }^{[28]}$ used a novel approach to extract information on isothermal kinetics from their non-isothermal DSC experiments, as already discussed. The validity of their approach was tested by comparing the TTT diagrams with the results of quantitative X-ray phase diffraction analysis (QXRPDA). However, further validation of this approach from other independent investigations may be necessary to prove its suitability in the study of isothermal crystallization kinetics of mold fluxes.

\section{B. Single and Double Hot Thermocouple Techniques (SHTT, DHTT)}

The hot thermocouple driver is a unique driver in which the temperature can be simultaneously monitored while a thermocouple is heated. In this method, the slag can be directly melted on the tip of a thermocouple or between two similarly configured thermocouples. There are two different modes of operation for the hot thermocouple technique viz. the SHTT and the DHTT. The SHTT has been in use in metallurgical applications for quite some time. Ordway ${ }^{[32]}$ first used this technique in the year 1952 to study the growth of single crystals of refractory compounds precipitating out from a melt at temperatures up to $1600{ }^{\circ} \mathrm{C}$. Ohta et al. ${ }^{[33]}$ used this technique for determining the liquidus temperatures of slags and for elucidating the mechanism of slag-metal reactions. Asayama et al. ${ }^{[34]}$ also used the SHTT for experiments with slags to study glass formation in silicate systems. In one of the first studies of its kind, Kashiwaya et al. ${ }^{[35]}$ applied the SHTT technique for studying the isothermal crystallization kinetics of $\mathrm{CaO}-\mathrm{SiO}_{2}-\mathrm{Al}_{2} \mathrm{O}_{3}-\mathrm{Na}_{2} \mathrm{O}$-based mold fluxes. Also, the DHTT which was developed by Kuranaga et al., ${ }^{[36]}$ Murayam et al., ${ }^{[37]}$ and Uhlman ${ }^{[38]}$ for an earlier study on microgravity experiments, was used in this work by Kashiwaya et al. ${ }^{[35]}$ to study isothermal crystallization kinetics. Schematic representations of the SHTT and DHTT are given in Figure 5.

Kashiyama et al. ${ }^{[35]}$ observed the crystallization phenomenon using a video equipment. They recorded the onset of crystallization and measured the growth rate of the solidification front as a function of the cooling rate. For their isothermal experiments, they melted the decarburized mold flux samples on the thermocouples at temperatures practically experienced in the continuous casting mold when the liquid slag is in contact with the liquid steel $\left(\sim 1500^{\circ} \mathrm{C}\right)$. At the melting temperature, the slag was homogenized and then cooled to a given temperature with a high cooling rate $\left(\sim 80{ }^{\circ} \mathrm{C} \mathrm{s}^{-1}\right)$ and then held for 30 to 60 minutes until crystallization was complete. They reported that the crystallization initiated within 10 to 400 seconds of the isothermal holding and the crystals grew for up to 45 minutes after the start of crystallization. With their data, Kashiyama et al. ${ }^{[35]}$ constructed the time-temperature-transformation (TTT) diagrams for the relevant systems and determined the effects of $\mathrm{Na}_{2} \mathrm{O}$ additions in $\mathrm{CaO}-\mathrm{SiO}_{2}-\mathrm{Al}_{2} \mathrm{O}_{3}$-based
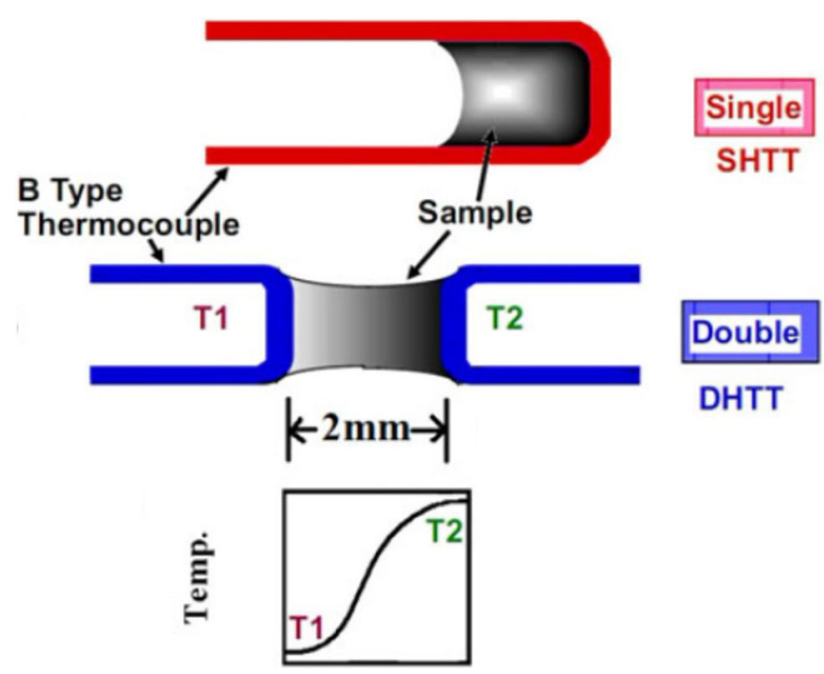

Fig. 5-Schematic representations of the SHTT and DHTT (reproduced with permission from Kashiwaya et al. ${ }^{[35]}$ ). 
mold fluxes. They reported that $\mathrm{Na}_{2} \mathrm{O}$ had a major effect on the isothermal crystallization kinetics with both the nose temperature and the incubation time for crystallization decreasing with increasing $\mathrm{Na}_{2} \mathrm{O}$ content, as shown in Figure 6. ${ }^{[35]}$

Following the work by Kashiyama et al.,${ }^{[35]}$ several other researchers have used the SHTT and DHTT in the study of crystallization kinetics of conventional mold slags. ${ }^{[8,}$ 39-44] Orrling et al. ${ }^{[39]}$ studied the isothermal crystallization kinetics of a $\mathrm{CaO}-\mathrm{SiO}_{2}-\mathrm{Al}_{2} \mathrm{O}_{3}-\mathrm{Na}_{2} \mathrm{O}$ $\mathrm{CaF}_{2}$ mold slag using the DHTT. They also constructed the TTT diagram for the onset of crystallization in the mold slag over a wide range of temperature ranging from 800 to $1300{ }^{\circ} \mathrm{C}$. Their observations further confirmed that the incubation period decreases with increasing $\mathrm{Na}_{2} \mathrm{O}$ content in the slag. Furthermore, they also reported that the addition of $\mathrm{CaF}_{2}$ promotes crystallization in the slag. Depending on the degree of undercooling, they reported different morphologies of the precipitated crystals. They were classified into four different types: (a) equiaxed crystals at low degree of undercooling, (b) columnar crystals that grew from the thermocouples towards the center of the sample, (c) dendritic crystals with a faceted shape that occurred across the whole sample, and (d) very fine crystals that only appeared in samples with a large degree of undercooling.

Wen et al. ${ }^{[40]}$ also studied the isothermal crystallization kinetics of four $\mathrm{CaO}-\mathrm{SiO}_{2}-\mathrm{Na}_{2} \mathrm{O}-\mathrm{CaF}_{2}$-based industrial mold fluxes using the SHTT. As predicted by the classical nucleation theory, they observed that the onset time for crystallization first decreased and then increased thereby giving rise to a "C-curve." Another important result from their study is that the entire crystallization phenomenon was divided into two C-curves which intersected at $\sim 1100{ }^{\circ} \mathrm{C}$, as shown in Figure 7. This meant that two separate nucleation events were taking place and that different phases were crystallized at different temperatures. From the XRD studies performed by the authors, the two crystalline phases were identified as cuspidine $\left(\mathrm{Ca}_{4} \mathrm{Si}_{2} \mathrm{O}_{7} \mathrm{~F}_{2}\right)$ at temperatures above $1100{ }^{\circ} \mathrm{C}$ and calcium silicon oxide fluoride $\left(\mathrm{Ca}_{2} \mathrm{SiO}_{2} \mathrm{~F}_{2}\right)$ at temperatures below $1100{ }^{\circ} \mathrm{C}$.

Zhou et al. ${ }^{[41]}$ studied the effect of basicity on the crystallization of $\mathrm{CaO}-\mathrm{SiO}_{2}-\mathrm{Al}_{2} \mathrm{O}_{3}-\mathrm{CaF}_{2}$-based fluxes using the SHTT and they, too, constructed the TTT diagrams for these fluxes. They reported that an increase in basicity enhanced crystallization with both the incubation time and the effective activation energy for crystallization becoming smaller for higher basicity fluxes. For slags with basicity in the range from 1.0 to $1.2, \mathrm{CaSiO}_{3}$ was seen to precipitate in the upper part of the TTT diagram while cuspidine $\left(\mathrm{Ca}_{4} \mathrm{Si}_{2} \mathrm{O}_{7} \mathrm{~F}_{2}\right)$ was formed in the lower part. However, when the basicity was 0.8 , only cuspidine was seen to crystallize. The crystallization mechanism of cuspidine was reported to change from one-dimensional growth to three-dimensional growth with a constant nuclei when the basicity was increased from 0.8 to $1.2 .^{[41]}$

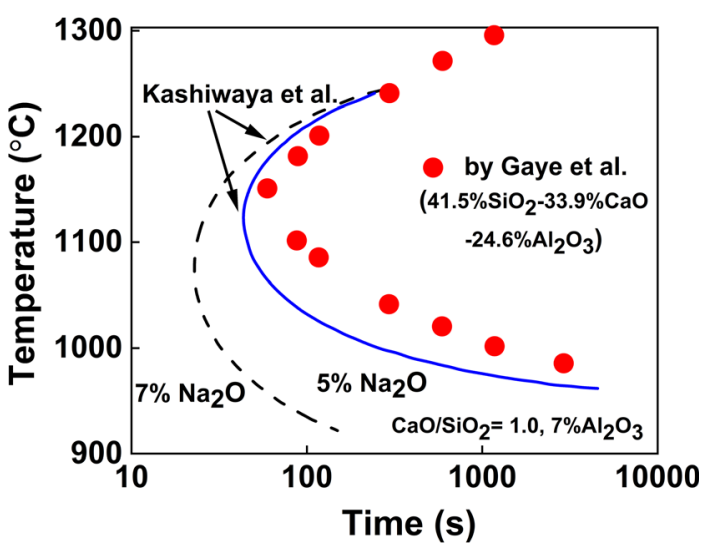

Fig. 6-Effect of $\mathrm{Na}_{2} \mathrm{O}$ addition on the isothermal crystallization kinetics of $\mathrm{CaO}-\mathrm{SiO}_{2}-\mathrm{Al}_{2} \mathrm{O}_{3}$-based mold fluxes as observed by Kashiwaya et al. ${ }^{[35]}$ (reproduced with permission from Kashiwaya et al. ${ }^{[35]}$ ).

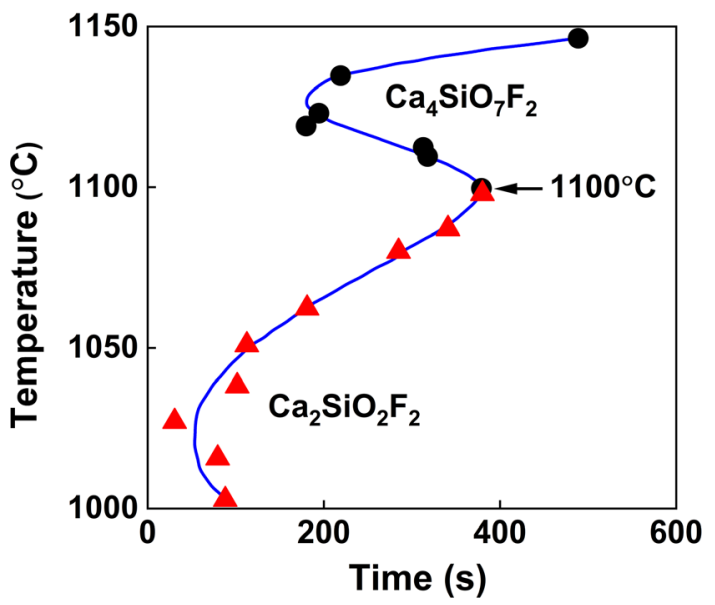

Fig. 7-TTT diagram of a $\mathrm{CaO}-\mathrm{SiO}_{2}-\mathrm{Na}_{2} \mathrm{O}-\mathrm{CaF}_{2}$-based industrial mold flux obtained by Wen et al. ${ }^{[40]}$ (reproduced with permission from Wen et al. ${ }^{[40]}$ ).

Petajajarvi et al. ${ }^{[42]}$ used the SHTT to study the crystallization behavior of four different industrial mold fluxes used in Outokumpu Tornio Works and constructed the respective TTT diagrams. In addition, these authors compared the results obtained from SHTT experiments to the measured heat flux values from the two continuous casting machines. As pointed out by the authors, some discrepancy between the TTT results and the behavior in the continuous casting machines was observed because, contrary to expectations, the mold flux with the highest tendency to crystallize did not have the lowest thermal conductivity. The authors did not present a suitable explanation for this discrepancy although an attempt was made to explain this behavior in terms of the differences in viscosities and break temperatures of the mold fluxes studied. ${ }^{[42]}$ 
With the recent developments in the field of advanced high-strength steels (AHSS), certain amounts of Al are often added into these steels and this results in a significant amount of interaction between the $\mathrm{SiO}_{2}$ in the mold slag and Al in the molten metal, as already discussed. Therefore, sincere efforts have been made by researchers in recent years to find an alternative flux for casting these steel grades and often a $\mathrm{CaO}-\mathrm{Al}_{2} \mathrm{O}_{3}$-based mold flux system is proposed. In a recent review article, Wang et al. ${ }^{[43]}$ have summarized the latest developments for this new mold flux system. Yan et al. ${ }^{[44]}$ studied the crystallization behavior of mold fluxes based on a $\mathrm{CaO}-\mathrm{Al}_{2} \mathrm{O}_{3}$ system, which is used in the casting of high-Al non-magnetic steels containing 1.5 to $2.5 \mathrm{wt}$ pct Al. The mold fluxes studied by these authors were much richer in $\mathrm{Al}_{2} \mathrm{O}_{3}$ and, therefore, much leaner in $\mathrm{CaO}$ and $\mathrm{SiO}_{2}$ as compared to conventional mold fluxes. Their TTT results indicated that an increase in $\mathrm{Al}_{2} \mathrm{O}_{3} / \mathrm{SiO}_{2}$ enhanced the crystallization phenomena by increasing the initial crystallization temperature and nose temperature, and shortening the incubation time. On the other hand, when $\mathrm{CaO}$ was substituted with $\mathrm{BaO}$ in the mold fluxes, crystallization was suppressed as manifested by the decrease in the initial crystallization temperature and nose temperature, and an increase in the incubation time. ${ }^{[44]}$

Also, conventionally, mold fluxes used in continuous casting of steel consists of oxides and fluorides. The fluorine is usually present in the form of $\mathrm{CaF}_{2}$. Oxy-fluoride systems are usually unstable since they react to form gaseous fluorides. ${ }^{[1]}$ These gaseous fluorides often react with any moisture present to form $\mathrm{HF}$ gas that cause a severe health and safety problem and is responsible for corrosion of plant equipment. Moreover, the secondary cooling water leaches the fluoride out of the spent slag film at the mold exit and the water gradually becomes acidic. Consequently, the cooling water has to be treated with alkaline agents to restore its normal $\mathrm{pH}$ level. For these reasons, in the recent past, there has been a search for mold powders containing zero, or reduced, levels of $\mathrm{CaF}_{2}$. However, as already discussed, the challenge is to replace cuspidine which is the predominant crystalline phase in conventional F-containing fluxes with a suitable crystalline phase that would meet the required thermal resistance which is dependent upon both $f_{\text {crys }}$ and $R_{C u / s l}$. Nakada and Nagata ${ }^{[8]}$ proposed a $\mathrm{CaO}-\mathrm{SiO}_{2}-\mathrm{TiO}_{2}$-based mold flux as a substitute for $\mathrm{CaO}-\mathrm{SiO}_{2}-\mathrm{CaF}_{2}$-based fluxes and reported that rapid crystallization of $\mathrm{CaSiTiO}_{5}$ takes place in this system with incubation time less than that of cuspidine. Wen et al..$^{[45]}$ also used a $\mathrm{CaO}-\mathrm{SiO}_{2}-\mathrm{TiO}_{2}-$ based system starting from a Ti-bearing blast furnace (BF) slag to substitute the conventional fluorine containing mold fluxes for casting peritectic steels. They observed the crystallization of perovskite $\left(\mathrm{CaTiO}_{3}\right)$ as the dominant crystalline phase instead of cuspidine and plant trials indicated that heat transfer in the mold was well controlled using this new flux. One problem associated inherently with the use of $\mathrm{CaO}-\mathrm{SiO}_{2}-\mathrm{TiO}_{2}-$ based fluxes is the increase in sticker breakouts. Wang et al. ${ }^{[46]}$ contended that one of the possible reasons for this phenomenon is the formation of $\operatorname{TiN}$ and $\operatorname{Ti}(\mathrm{C}, \mathrm{N})$ and these authors have used thermodynamic calculations and laboratory trials to validate this claim. Zhou et al.$^{[47]}$ were among the first researchers to propose the use of higher amounts of $\mathrm{Na}_{2} \mathrm{O}, \mathrm{Li}_{2} \mathrm{O}$, and $\mathrm{B}_{2} \mathrm{O}_{3}$ in the mold flux as substitutes for $\mathrm{CaF}_{2}$ in the conventional fluorine-containing fluxes. They studied the crystallization kinetics of these fluxes using the SHTT/DHTT and reported that the crystallization temperatures of these F-free mold fluxes increased with the increasing basicity and $\mathrm{Na}_{2} \mathrm{O} / \mathrm{Li}_{2} \mathrm{O}$ contents. The main crystalline phase formed in the designed $\mathrm{F}$-free mold fluxes was found to be calcium borosilicate $\left(\mathrm{Ca}_{11} \mathrm{Si}_{4} \mathrm{~B}_{2} \mathrm{O}_{22}\right)$ and the authors concluded that a F-free mold flux with basicity $\sim 1.15$, $\mathrm{Na}_{2} \mathrm{O} \sim 8$ wt pct, $\mathrm{Li}_{2} \mathrm{O} \sim 2.0$ wt pct, and $\mathrm{B}_{2} \mathrm{O}_{3} \sim 6.0$ wt pct would have similar performance to that of conventional mold flux having a basicity of $\sim 1.25$ and a fluorine content of $\sim 7.25 \mathrm{wt}$ pct. ${ }^{[47]}$

Yang et al..$^{[48]}$ studied the effects of $\mathrm{MgO}$ on the isothermal crystallization kinetics of F-free mold fluxes using the SHTT/DHTT technique and reported that the crystallization tendency increased with increasing $\mathrm{MgO}$ additions in the flux. The main crystalline phase was observed to change from $\mathrm{CaSiO}_{3}$ to $\mathrm{CaSiO}_{3} / \mathrm{Ca}_{2} \mathrm{Mg}$ $\mathrm{Si}_{2} \mathrm{O}_{7} / \mathrm{Ca}_{11} \mathrm{Si}_{4} \mathrm{~B}_{2} \mathrm{O}_{22}$, and finally $\mathrm{Ca}_{2} \mathrm{MgSi}_{2} \mathrm{O}_{7}$ as the $\mathrm{MgO}$ content was increased. The heat flux across the mold fluxes, however, was found to decrease with an increase in $\mathrm{MgO}$ content. Chen et al. ${ }^{[49]}$ studied the effects of $\mathrm{Al}_{2} \mathrm{O}_{3}$ and $\mathrm{MgO}$ additions on the isothermal crystallization kinetics of $\mathrm{CaO}-\mathrm{SiO}_{2}-\mathrm{B}_{2} \mathrm{O}_{3}$-based fluorine-free mold fluxes containing significant amounts of $\mathrm{Na}_{2} \mathrm{O}$ and $\mathrm{Li}_{2} \mathrm{O}$ using the SHTT. Their results suggest that crystallization was first inhibited and then enhanced with $\mathrm{Al}_{2} \mathrm{O}_{3}$ addition while $\mathrm{MgO}$ was seen to monotonically promote crystallization when added in the range of 2-10 wt. pct. These authors further used Fourier transform infrared (FTIR) spectroscopy and Raman spectroscopy to relate the structure of the mold slag with the composition. They observed that consistent with the crystallization behavior of the mold fluxes, $\mathrm{Al}_{2} \mathrm{O}_{3}$ served as a network former when added in the range 4 to $8 \mathrm{wt}$ pct while it served as a network breaker when the $\mathrm{Al}_{2} \mathrm{O}_{3}$ content was further increased to 8 to $12 \mathrm{wt}$ pct $\mathrm{MgO}$. On the other hand, when added in the range 2 to $6 \mathrm{wt}$ pct $\mathrm{MgO}$ provided $\mathrm{Mg}^{2+}$ cation in the melt which had the charge-compensation effect and also led to a slight increase in the Al-O-Al and B-O-B structural units in the slag. For higher contents of $\mathrm{MgO}$, in the range 6 to 10 wt pct, the continuous addition of $\mathrm{O}^{2-}$ was found to further depolymerize the melt and cause faster crystallization. ${ }^{[49]}$

Other investigations on the use of SHTT and DHTT for studying the isothermal crystallization behavior of mold fluxes in continuous casting can be found in the studies by Klug et al.$^{[50]}$ and Jiang et al. ${ }^{[51]}$ For the sake of brevity, discussions on these papers are not included here. In a recent review article, Kölbl et al. ${ }^{[52]}$ have summarized the findings from these investigations. Interested readers are referred to the original publications ${ }^{[50,51]}$ and the review paper by Kölbl et al. ${ }^{[52]}$ for more information. 
In this section, the studies available in the literature on the isothermal crystallization kinetics of mold fluxes using the SHTT and DHTT have been summarized. Because of the high cooling rates that can be achieved using the hot thermocouple technique, this technique can be suitably used for studying the crystallization behavior for large degrees of undercooling. Also, using this technique, the crystallization phenomena of mold fluxes can be observed in situ which was a unique feature at a time when the CSLM was still relatively unknown in metallurgical applications. Kashiwaya et al. ${ }^{[35]}$ have been the pioneers in the application of this technique to the study of mold slag crystallization following which several other researchers have used this technique for the same application. The studies by Kashiwaya et al. ${ }^{[35]}$ and Orrling et $a{ }^{\left[{ }^{[39]}\right.}$ elucidated the roles of alkali oxide additions and both of them found that the kinetics of crystallization are enhanced because of alkali oxide additions. Orrling et al. ${ }^{[39]}$ also constructed a map for the morphology of the precipitated crystals as a function of the degree of undercooling while Wen et al. ${ }^{[40]}$ successfully observed multiple crystallization phenomena in $\mathrm{CaO}-\mathrm{SiO}_{2}-\mathrm{Na}_{2} \mathrm{O}-\mathrm{CaF}_{2}$-based mold fluxes using the SHTT. Zhou et al. ${ }^{[41]}$ observed that an increase in basicity enhances the isothermal crystallization kinetics of conventional $\mathrm{CaO}-\mathrm{SiO}_{2}-\mathrm{Al}_{2} \mathrm{O}_{3}-\mathrm{CaF}_{2}$-based mold fluxes. Yan et al. ${ }^{[4]}$ observed that with increasing $\mathrm{Al}_{2} \mathrm{O}_{3} / \mathrm{SiO}_{2}$ ratio, crystallization was enhanced in high $\mathrm{Al}_{2} \mathrm{O}_{3}$-containing mold fluxes while $\mathrm{BaO}$ substitution was seen to suppress crystallization. In addition, there are several studies available in the literature on the crystallization kinetics of relatively newer fluorine-free fluxes as already discussed in the preceding paragraphs. ${ }^{[47-49]}$ Therefore, several important information on the effects of individual components present in the mold flux on the crystallization kinetics and the crystal morphology can be obtained from these studies for both conventional and high $\mathrm{Al}_{2} \mathrm{O}_{3}$ as well as fluorine-free mold fluxes, as discussed.

\section{Confocal Scanning Laser Microscopy (CSLM)}

The high-temperature CSLM is an in situ direct observation device used for studying crystallization in undercooled melts. The CSLM uses a halogen infrared (IR) heating lamp, which is focused on a small crucible placed on a holding plate to which a thermocouple is attached, as shown in Figure 8. The image of the specimen can be detected using the difference in contrast obtained from the scanning laser, which is typically in the red, blue or violet wavelength range. ${ }^{[53]}$ Emi et al. ${ }^{[54-56]}$ initially used this equipment to study the solidification behavior and high-temperature solid-state phase transformation in steels. Over the last two decades, better resolution has been realized in the CSLM leading to higher quality images and higher cooling rates have been achieved. In view of its extra-ordinary capability to make in situ observations, the CSLM is now being used as a tool to study the solidification phenomena related to the continuous casting of steel. Because of its versatility, it can be used to study crystallization kinetics under both isothermal and non-isothermal conditions. In this section, the available literature on the isothermal crystallization kinetics of mold fluxes used for continuous casting of steel has been reviewed. In a subsequent section, the relevant literature on non-isothermal crystallization kinetics will be reviewed.

Zhang et al. ${ }^{[57]}$ investigated the isothermal crystallization kinetics of $\mathrm{CaO}-\mathrm{SiO}_{2}-\mathrm{Al}_{2} \mathrm{O}_{3}-\mathrm{CaF}_{2}$-based mold fluxes used in the continuous casting of transformation induced plasticity (TRIP) steels under isothermal conditions using a CSLM. Their objective was to study the effect of $\mathrm{Al}_{2} \mathrm{O}_{3} / \mathrm{SiO}_{2}$ ratio on the crystallization behavior. Using the CSLM observations, they constructed the TTT diagrams for the start of crystallization for mold fluxes of different $\mathrm{Al}_{2} \mathrm{O}_{3} / \mathrm{SiO}_{2}$ ratios and reported that the crystallization start temperature increased while incubation time decreased sharply with increasing $\mathrm{Al}_{2} \mathrm{O}_{3} / \mathrm{SiO}_{2}$ ratios. Two of these TTT diagrams, as reported by Zhang et al., ${ }^{[57]}$ are shown in Figure 9. The crystal morphology was also reported to change with the chemical composition and the isothermal holding temperature. The crystallization path, as reported by these authors, was found to be complex with $\mathrm{CaF}_{2}$ precipitating first followed by a second phase whose composition changed from cuspidine to gehlenite as the $\mathrm{Al}_{2} \mathrm{O}_{3} /$ $\mathrm{SiO}_{2}$ ratio increased above 0.65 . Finally, for mold fluxes with $\mathrm{Al}_{2} \mathrm{O}_{3} / \mathrm{SiO}_{2}$ ratios greater than 1.42 a third $\mathrm{Al}_{2} \mathrm{O}_{3}$ phase was found to precipitate. The authors also measured the growth rate of crystals using successive CSLM images and reported that it increased exponentially with increasing isothermal holding temperature.

Ryu et al. ${ }^{[58]}$ also investigated the effects of basicity and alumina content on the crystallization behavior of mold fluxes used in TRIP steels using a CSLM. Their objective was to elucidate the difference in crystallization behavior for model mold slags of different compositions and correlate this to changes in the horizontal heat flux during the casting process. Three different levels of alumina content were chosen for their study to investigate this difference viz. 3,15 , and $20 \mathrm{wt}$ pct $\mathrm{Al}_{2} \mathrm{O}_{3}$ and the TTT diagrams were constructed for all the mold flux systems. Similar to the observations of Zhang et al., ${ }^{[57]}$ they too reported that the crystallization temperature increased and the incubation time decreased with increasing basicity and alumina content. They also reported that the increase in alumina content induced the precipitation of $\mathrm{CaF}_{2}$ during cooling and hence the primary crystalline phase changed from $\mathrm{Ca}_{4} \mathrm{Si}_{2} \mathrm{O}_{7} \mathrm{~F}_{2}$ in low $\mathrm{Al}_{2} \mathrm{O}_{3}$ mold fluxes to $\mathrm{Ca}_{2} \mathrm{Al}_{2} \mathrm{SiO}_{7}$ in high $\mathrm{Al}_{2} \mathrm{O}_{3}$ fluxes.

Zhang et al. ${ }^{[58]}$ constructed the time-temperature-transformation (TTT) diagrams for F-free mold fluxes based out of a $\mathrm{CaO}-\mathrm{SiO}_{2}-\mathrm{Al}_{2} \mathrm{O}_{3}-\mathrm{Na}_{2} \mathrm{O}-\mathrm{B}_{2} \mathrm{O}_{3}$ system using a CSLM and similarly reported that the tendency of crystallization increased with increasing basicity. They also studied the effects of zirconia and titania additions in the mold flux and observed that zirconia addition enhanced the crystallization tendency due to its limited solubility in the mold slag and thereby acting as nucleation sites. In low basicity mold fluxes, 


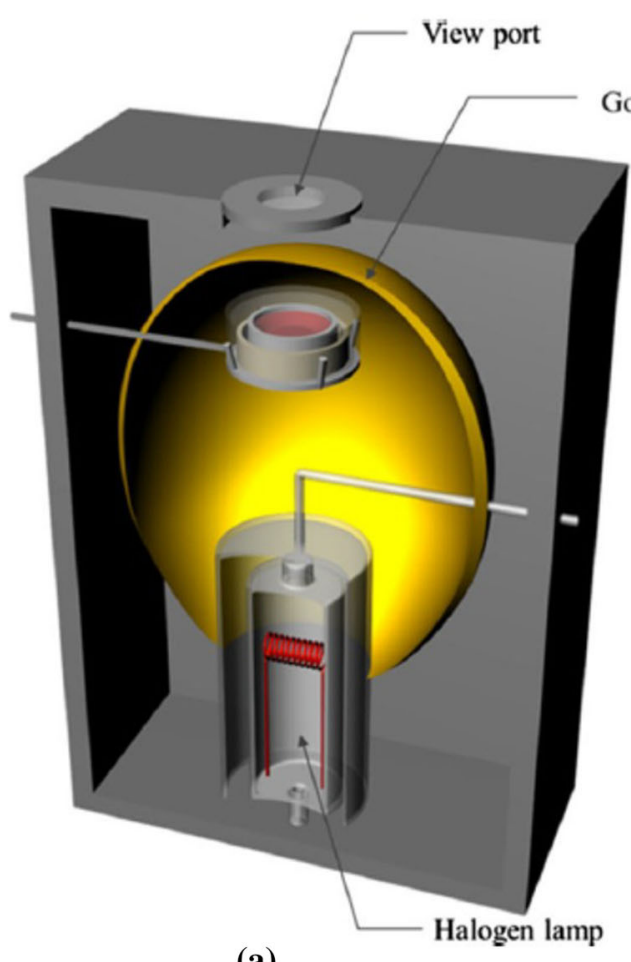

(a)
Gold coated chamber $\left(\mathrm{V}=792 \mathrm{~cm}^{3}\right)$

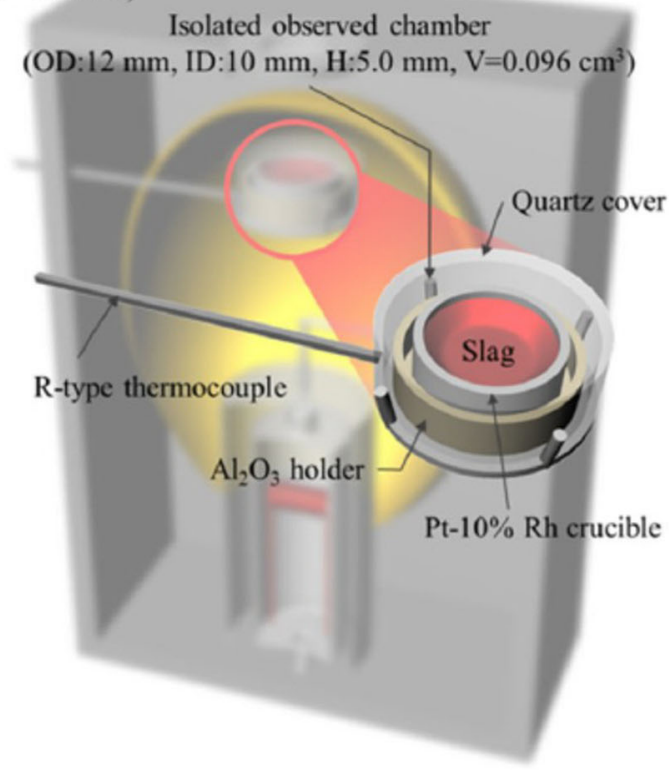

(b)

Fig. 8-Schematic representation of a confocal scanning laser microscopy (CSLM) - (a) gold-coated equipment chamber and (b) isolated observation chamber ${ }^{[33]}$ (reproduced with permission from Sohn et al. ${ }^{[53]}$ ).

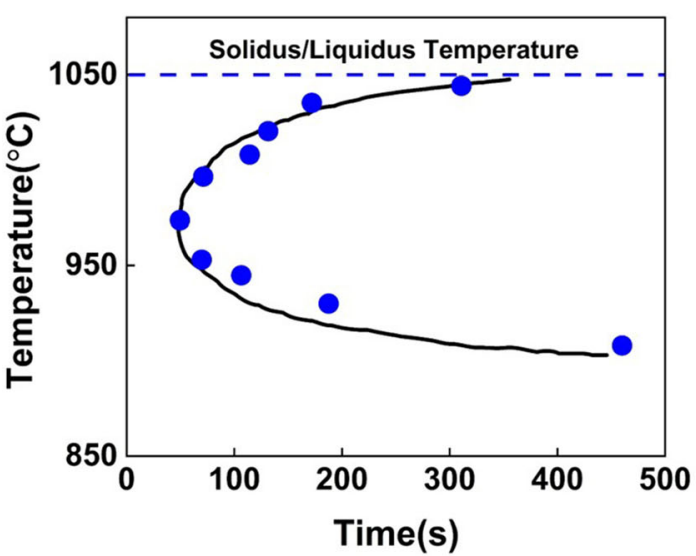

(a)

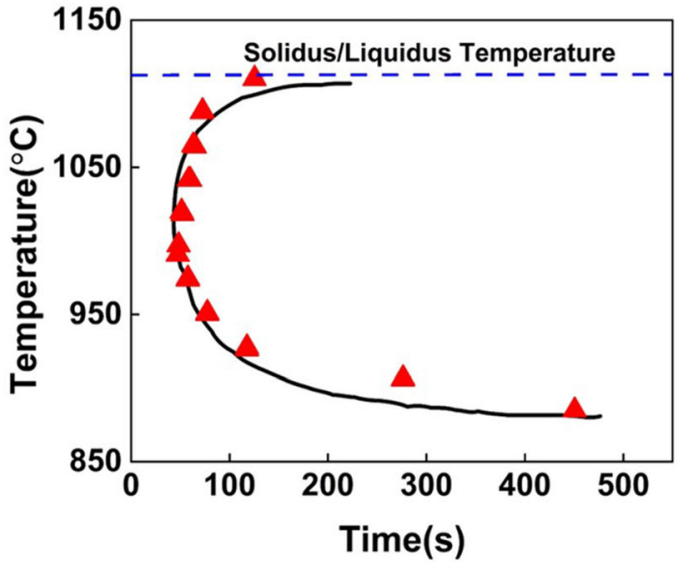

(b)

Fig. 9- TTT diagrams of two $\mathrm{CaO}-\mathrm{SiO}_{2}-\mathrm{Al}_{2} \mathrm{O}_{3}-\mathrm{CaF}_{2}$-based mold fluxes with varying $\mathrm{Al}_{2} \mathrm{O}_{3} / \mathrm{SiO}_{2}$ ratios as determined by $\mathrm{Zhang}$ et al. ${ }^{[57]}$ using CSLM- (a) $\mathrm{Al}_{2} \mathrm{O}_{3} / \mathrm{SiO}_{2}=0.65$ and $(b) \mathrm{Al}_{2} \mathrm{O}_{3} / \mathrm{SiO}_{2}=1.55$ (reproduced with permission from Zhang et al. ${ }^{[57]}$ ).

pseudo-wollastonite was found to be the main crystalline phase, whereas in high basicity mold fluxes, the crystalline phases were kilchoanite and larnite.

In the foregoing section, the studies on the isothermal crystallization kinetics of mold fluxes using the CSLM have been reviewed. The CSLM, because of its versatility, offers some distinct advantages over other techniques that are used for studying mold slag crystallization. Both Zhang et al. ${ }^{[57]}$ and Ryu et al. ${ }^{[58]}$ reported using their CSLM observations that with increasing $\mathrm{Al}_{2} \mathrm{O}_{3}$ content, crystallization in mold fluxes, which are used for casting of TRIP steels, gets significantly enhanced. It is also known from these two studies that the primary crystalline phase in the mold slags changed from $\mathrm{Ca}_{4} \mathrm{Si}_{2} \mathrm{O}_{7} \mathrm{~F}_{2}$ in low $\mathrm{Al}_{2} \mathrm{O}_{3}$ mold fluxes to $\mathrm{Ca}_{2} \mathrm{Al}_{2} \mathrm{SiO}_{7}$ in high $\mathrm{Al}_{2} \mathrm{O}_{3}$ fluxes. From the study by Zhang et al. ${ }^{[59]}$ for an F-free mold flux, it is known that the crystallization tendency of mold fluxes increases with increasing basicity. Also, their study showed that zirconia addition, too, enhanced 
crystallization because they acted as nucleation sites for the precipitating phase. Therefore, it can be concluded that the isothermal crystallization studies in CSLM have played a significant part in understanding the crystallization behavior of non-conventional mold fluxes. Continued efforts in this direction is expected to play an important role in the development of new and alternative (F-free) mold fluxes.

\section{NON-ISOTHERMAL CRYSTALLIZATION KINETICS OF MOLD FLUXES}

Non-isothermal kinetics, as opposed to isothermal kinetics, involve the study of the fraction transformed as function of time as the temperature continually changes. The studies on non-isothermal crystallization kinetics of mold fluxes, therefore, involve cooling of the molten flux continuously at specific cooling rates to a temperature much below the melting temperature. The crystallization kinetics are then calculated by determining the fraction transformed and the continuous cooling transformation (CCT) diagrams are then constructed. Figure 10 shows a schematic representation of the thermal cycle used in the experiments related to non-isothermal crystallization kinetics of mold fluxes.

As in the case of isothermal crystallization, crystallization kinetics under non-isothermal conditions are also studied using three main techniques viz. thermoanalytical techniques such as DSC/DTA, the SHTT and DHTT, and the CSLM. In the following sections, the available literature on non-isothermal crystallization kinetics based on these three different techniques has been reviewed.

\section{A. Thermoanalytical Techniques}

Thermoanalytical techniques such as DSC and DTA are widely used in the study of non-isothermal crystallization kinetics for glass-forming liquids. Therefore, these techniques are also very widely used in the investigation of non-isothermal crystallization kinetics of mold fluxes used for continuous casting of steel. In this section, the different methods used in the analyses of non-isothermal crystallization data are first discussed. Next, the individual studies on isothermal crystallization kinetics of mold fluxes using these methods are reviewed.

1. Common Methods Used in the Analysis of Non-isothermal Crystallization Kinetics Using DSC/ $D T A$

a. Kissinger method One of the methods that is used very often in the analyses of non-isothermal crystallization kinetics is the Kissinger method. ${ }^{[29,60]}$ The details of derivation for this method are not included here since they are already present in the original papers by Kissinger $^{[29,60]}$ and only the final form of the so-called Kissinger equation is mentioned as follows ${ }^{[29,60]}$ :

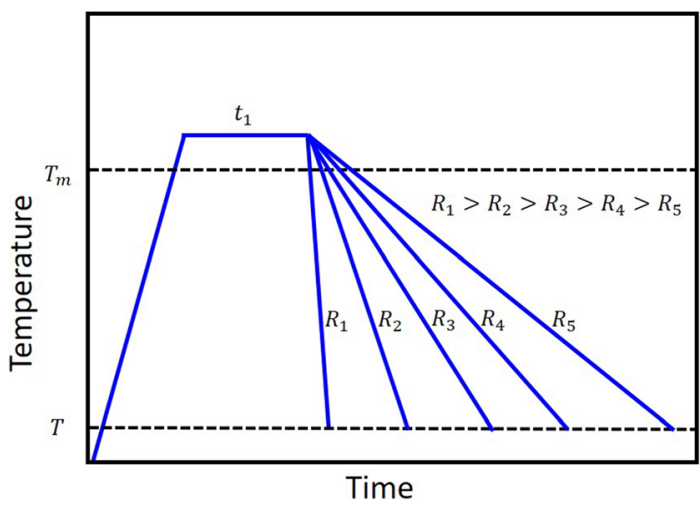

Fig. 10-Schematic of a typical thermal cycle used for non-isothermal crystallization experiments.

$$
\ln \left(\frac{\beta}{T_{p}^{2}}\right)=\ln \left(\frac{A R}{E}\right)-\frac{E}{R T_{p}} .
$$

Equation [11] is only strictly valid for first-order reactions. Likewise, for a reaction of order $r$, Eq. [10] can be obtained. ${ }^{[29,60]}$ Also, although Kissinger in his original work used a reaction order model for expressing the rate of the reaction, the general treatment is also applicable for all the different functional forms used to describe the rate of crystallization, i.e., $\frac{d X}{d t}$.

Kissinger $^{[31,60]}$ also suggested a simple method for calculating the order of the reaction from the DSC profiles. This was done first by proposing a "shape index," $S$, which is the absolute value of the ratio of the slope of the tangents at the inflection points. Analytically, this can be expressed as ${ }^{[60]}$

$$
S=\left|\frac{\left(\frac{d^{2} X}{d t^{2}}\right)_{1}}{\left(\frac{d^{2} X}{d t^{2}}\right)_{2}}\right| .
$$

In the above Eq. [12], subscripts 1 and 2 refer to the values of these quantities at the inflection points, i.e., where

$$
\left(\frac{d^{3} X}{d t^{3}}\right)=0 .
$$

Using a series of mathematical arguments and the approximation used by Murray and White, ${ }^{[24]}$ they calculated the value of $S^{1 / 2}$ which when plotted versus $r$ fell roughly on a straight line represented by the equation ${ }^{[60]}$

$$
r=1.26 S^{1 / 2}
$$

Therefore, Kissinger not only proposed an easy method for calculating the activation energy for the reaction but also proposed a very simple approach to calculate the reaction order from the shape of the DSC (or DTA) curve. Figure 11 shows a schematic representation of the methodology proposed by $\operatorname{Kissinger}^{[31,60]}$ to calculate the reaction order $(r)$ from a typical DSC curve. 


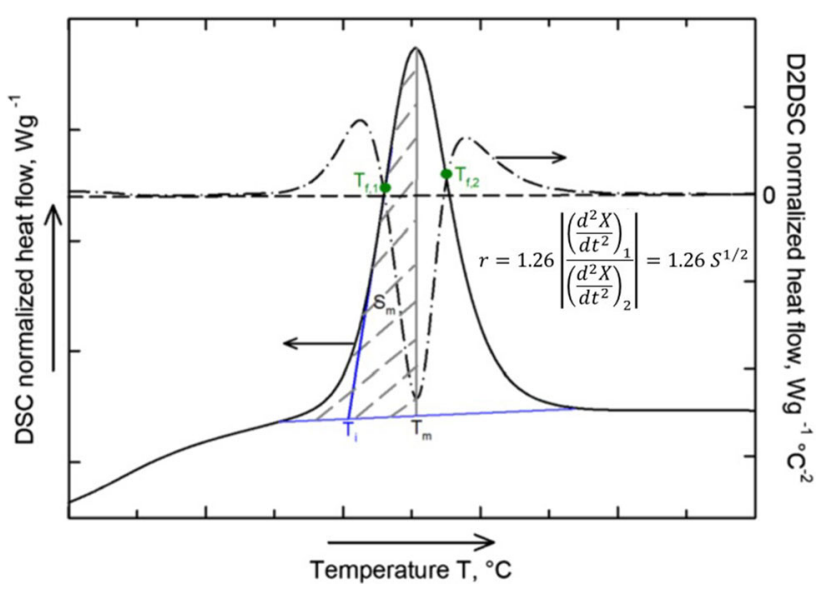

Fig. 11-Schematic representation of a DSC trace and Kissinger's method for calculating the reaction order from the shape index ${ }^{[31]}$ (reproduced with permission from Ref. [31]).

It must, however, be noted here that the original work by Kissinger ${ }^{[29,60]}$ was developed for the case when the transformations occur during heating. Crystallization in mold fluxes, on the other hand, take place as the mold slag is cooled at a particular cooling rate. On cooling, the temperature decreases with time giving rise to negative values of $\beta$. It is evident from Eqs. [8] and [9] that it does not permit the substitution of a negative value for the heating rate, $\beta$. This problem is sometimes bypassed by dropping the negative sign for the heating rate for continuous cooling experiments and using an absolute value for $\beta$. However, Vyazovkin ${ }^{[61,62]}$ critically assessed the validity of using the Kissinger equation for studying the transformation that takes place during cooling and concluded that, from a strictly mathematical viewpoint, dropping the negative sign of $\beta$ in order to make the Kissinger equation applicable for cooling experiments is an invalid exercise and might lead to unrealistic values of the activation energy. He suggested the use of isoconversional methods ${ }^{[62]}$ as an alternative to the Kissinger method for studying the non-isothermal kinetics of reactions that occurred during cooling. Nonetheless, the Kissinger method ${ }^{[29,60]}$ is still widely used for studying the non-isothermal crystallization kinetics of mold fluxes.

b. Method of Matushita and Sakka Matushita et $a l^{[63-67]}$ contended that the Kissinger equation, although simple and easy, is only strictly valid when the growth of the crystals takes place on a fixed number of nuclei and leads to an incorrect activation energy when the number of nuclei present is a function of the heating rate. They suggested a modification of the Kissinger which is briefly described as follows:

The crystal growth $(U)$ of nuclei of radius $\rho$ was expressed as ${ }^{[63]}$

$$
U=\frac{d \rho}{d t}=\beta \frac{d \rho}{d T}=U_{0} \cdot e^{-\frac{E}{R T}} \cdot\left(1-e^{-\frac{\Delta G}{R T}}\right) .
$$

Table I. Variation in the Values of $v, m$, and $r$ for the Different Mechanisms of Crystallization

\begin{tabular}{llll}
\hline & $v$ & $m$ & $r$ \\
\hline Bulk Nucleation & & & \\
3D Growth & 4 & 3 & 1 \\
2D Growth & 3 & 2 & 1 \\
1D Growth & 2 & 1 & 1 \\
Surface Nucleation & 1 & 1 & $2 / 3$ \\
\hline
\end{tabular}

Using Eq. [13] and a series of mathematical arguments which are skipped here, they derived a generalized expression for the growth rate of the crystallized nuclei as $^{[63]}$

$$
\frac{d X}{d t}=A \beta^{-(v-1)} \cdot e^{-m E / R T} \cdot(1-X)^{r},
$$

where $v, m$, and $r$ are all numerical constants whose values depend on the mechanism of nucleation as summarized in Table I. ${ }^{[66]}$

Matushita and Sakka ${ }^{[63]}$ then applied the same approach as followed by Kissinger ${ }^{[29,60]}$ and obtained the following equation ${ }^{[63]}$

$$
\ln \left(\frac{\beta^{v}}{T_{p}^{2}}\right)=\ln \left(\frac{A R r}{m E} \cdot(1-X)^{r-1}\right)-\frac{m E}{R T_{p}} .
$$

Using Eq. [17], the activation energy can be calculated using a plot similar to that of Kissinger. However, this requires that the value of $v$ and $m$ are first known.

In a later study, Matushita et al., ${ }^{[67]}$ improved the numerical accuracy of the approximation used in deriving Eq. [17] and modified it to the following equation $^{[67]}$ :

$$
\ln [-\ln (1-X)]=-v \cdot \ln \beta-1.052 \frac{m E}{R T}+\text { const. }
$$

Because the crystallized fraction at the peak temperatures is almost constant irrespective of the cooling rate, Eq. [16] is applicable at the peak temperature. The activation energy can then be calculated from the slope if the numerical factors are known. However, Shi et $a l^{[68]}$ pointed out that similar to the Kissinger method $^{[29,60]}$, the equations proposed by Matushita and Sakka ${ }^{[63-67]}$ are also strictly valid for studying crystallization during heating and may give rise to erroneous values of activation energy if they are used for studying crystallization during cooling (which is the phenomenon taking place in mold fluxes).

c. Method of Ozawa Equations [17] and [18] require the determination of the numerical factors $v$ (and $m$ ) to be known for calculating the activation energy for crystal growth. This is often done using the well-known Ozawa equation ${ }^{[69]}$ which is obtained by simply expressing the time variable $t$ as a function of temperature $T$ and heating rate $\beta$ as ${ }^{[69]}$

$$
t=\frac{T-T_{0}}{\beta} .
$$


Substituting Eq. [17] in the JMAK equation (Eq. [4]) gives after some manipulation ${ }^{[69]}$

$$
\ln (-\ln (1-X))=n \cdot \ln \left[K\left(T-T_{0}\right)\right]-n \cdot \ln \beta .
$$

From Eq. [20] we get

$$
\left.\frac{d\{\ln (-\ln (1-X))\}}{d \ln \beta}\right|_{T}=-n .
$$

It is evident from Eq. [21] that the plot of $\ln (-\ln (1-X))$ at the same temperature for a variety of heating rates should yield the value of $n$. This is known as the Ozawa equation after Ozawa. ${ }^{[69]}$

d. Method of Freeman and Carroll The method proposed by Freeman and Carroll ${ }^{[70]}$ assumes the rate of reaction to be expressed as ${ }^{[70]}$

$$
\frac{d X}{d t}=-k \cdot X^{a}
$$

Assuming a linear variation between time and temperature, they derived an equation of the following form: ${ }^{[70]}$

$$
\frac{\frac{-E}{R} \cdot \Delta\left(\frac{1}{T}\right)}{\Delta \ln X}=\frac{\Delta \ln \left(-\frac{d X}{d t}\right)}{\Delta \ln X}-a .
$$

It is, therefore, evident from Eq. [23] that a plot of $\frac{\Delta\left(\frac{1}{T}\right)}{\Delta \ln X}$ vs. $-\frac{\Delta \ln \left(-\frac{d X}{d t}\right)}{\Delta \ln X}$ will yield the activation energy $(E)$. However, this treatment is only strictly valid for reactions, which obey the rate law mentioned in Eq. [22]. In addition, it has been assumed in the treatment that the order of reactions does not vary during the transformation, which may not always hold true. In fact, Dooren and Muller ${ }^{[71]}$ have shown that for cases where the reaction order changes during the transition, the activation energy cannot be obtained from the Freeman and Carroll method using a linear model. In a later study, Jerez ${ }^{[72]}$ proposed a modified version of the Freeman and Carroll method for calculating the activation energy. However, his method was only related to improving the mathematical accuracy of the original model and did not address the fundamental question as to how this method can be applied to reactions not following the rate law mentioned in Eq. [22].

e. Method of Borchardt and Piloyan The method of Borchardt ${ }^{[73]}$ and Piloyan et al.$^{[74]}$ involves the differentiation of the JMAK equation (Eq. [4]) which gives ${ }^{[73,74]}$

$$
\dot{X}=(1-X) \cdot n K^{n} \cdot t^{n-1} \cdot(1+c t),
$$

where

$$
c=\frac{E \beta}{R T^{2}}=\frac{E}{R T^{2}} \cdot \frac{\left(T-T_{0}\right)}{t} .
$$

Based on the assumption that the starting temperature $T_{0}$ is much smaller than the temperature $T$ (i.e., $T \gg T_{0}$ ), and further assuming that $c t$ (i.e. $E / R T$ as per Eq. [25]) is much smaller than 1, Eq. [24] becomes

$$
\dot{X}=(1-X) \cdot n K^{n} \cdot t^{n-1} .
$$

In the method of Borchardt and Piloyan, the crystallization rate $\dot{X}$ is assumed proportional to the temperature difference measured in DTA, $\Delta T$ as ${ }^{[73,74]}$

$$
\dot{X}=B \cdot \Delta T,
$$

where $B$ is the proportionality constant.

Combining Eq. [26] with Eq. [27] and performing some mathematical operations, we get ${ }^{[73,74]}$

$$
\ln \Delta T=\ln [\varphi(X)]+\ln K_{0} n-\frac{-E}{R T}+\text { const },
$$

where

$$
\varphi(X)=(1-X) \cdot[-\ln (1-X))]^{(n-1) / n} .
$$

Borchardt ${ }^{[73]}$ and Piloyan et al ${ }^{[74]}$ further pointed out that the function in Eq. [29] is a constant in the range $0.25<X<0.5$ even for values of $n$ greater than one. It follows, therefore, that by plotting $\ln (\Delta T)$ versus $1 / T$, the activation energy $(E)$ can be obtained. However, as pointed out by Yinnon and Uhlmann ${ }^{[75]}$, the assumption that $c t=\frac{E}{R T} \ll 1$ is not valid in most crystallization events and therefore this method suffers from an inherent limitation. Nevertheless, the method of Borchardt $^{[73]}$ and Piloyan et al. ${ }^{[74]}$ is often used for calculating the activation energy in many crystallization processes.

f. Friedman isoconversional method The isoconversional method of Friedman is given as ${ }^{[76]}$

$$
\ln \left(\frac{d X}{d t}\right)_{X}=\frac{-E_{X}}{R T}+\text { const },
$$

where $E_{X}$ is the effective activation energy for a particular value of the fraction crystallized, $X$.

Using Eq. [28], the activation energy of any crystallization event corresponding to a particular value of fraction crystallized can be calculated and it can be verified whether the activation energy is independent of $X$.

g. Augis-Bennett method Another method that has been commonly used for the calculation of the Avrami exponent is the Augis-Bennett method. ${ }^{[77]}$ This method deals with the double differentiation of the JMAK equation (Eq. [4]) twice with respect to $t$ which gives $^{[77]}$

$$
\ddot{X}=\left[\ddot{u} u-\dot{u}^{2}\left(n u^{n}-n+1\right)\right] n u^{n-2}(1-X),
$$

where

$$
u=K t=K_{0} \cdot \exp \left(-\frac{E}{R T}\right) t .
$$

Further details for this method are skipped here and only the final form of the equation is mentioned as follow: ${ }^{[77]}$ 


$$
\log K_{0}-\frac{E}{R T_{p}}=\log \left(\frac{\beta}{T_{p}-T_{0}}\right)
$$

It is evident from Eq. [33] that a plot of $\log \left(\frac{\beta}{T_{p}-T_{0}}\right) v s$. $\frac{1}{T_{p}}$ will yield activation energy $(E)$. Further, using a Taylor series expansion of the first derivative of the fraction transformed around $T=T_{p}$, Augis and Bennett ${ }^{[77]}$ proposed the following equation for the calculation of the Avrami exponent $(n)$ as ${ }^{[77]}$

$$
n=\frac{2.5}{\Delta T_{p}} \cdot \frac{T_{p}^{2}}{\left(\frac{E}{R}\right)},
$$

where $\Delta T_{p}$ is the full width at half maximum of the DSC/DTA peak. Equation [34] is the well-known Augis-Bennett equation and using this equation, the Avrami parameter $(n)$ can be calculated. Figure 12 is a schematic representation of the Augis-Bennett method $^{[77]}$ used for calculating the Avrami parameter (n) from a DSC/DTA curve.

\section{Studies on Non-isothermal Crystallization Kinetics} of Mold Fluxes Using Thermoanalytical Techniques

In the preceding section, the different methods of analyzing the data on non-isothermal crystallization kinetics have been discussed. In this section, a review of the work done on non-isothermal crystallization kinetics of mold fluxes will be presented.

Seo et al. ${ }^{[78]}$ studied the non-isothermal crystallization kinetics of cuspidine formation in $\mathrm{CaO}-\mathrm{SiO}_{2}-\mathrm{CaF}_{2}-$ based mold fluxes using DSC. They first applied the well-known Ozawa equation ${ }^{[69]}$ to determine the Avrami parameter $(n)$. However, the plot of $\ln (-\ln (1-X))$ versus the heating rate $(\beta)$ at a constant temperature deviated significantly from linearity and this led them to the conclusion that the Ozawa analysis was not valid to the analysis of non-isothermal melt crystallization in the system of interest. Thereafter, they applied the isoconversion method developed by Friedman ${ }^{[76]}$ and determined the effective activation energy of cuspidine formation for the mold fluxes studied in the range -241 to $-652 \mathrm{~kJ} \mathrm{~mol}^{-1}$, respectively. This effective activation energy was found to remain constant over the range $X=0.1$ to 0.4 , whereas it increased as $X$ exceeded 0.4. Also, as already discussed, the negative effective activation energy indicated an anti-Arrhenius behavior, which meant that, for the mold fluxes studied, crystallization was determined by the thermodynamic driving force for nucleation related to the degree of undercooling. This postulation was further supported by the morphology of cuspidine as observed using the SEM, which also hinted towards an anti-Arrhenius behavior during non-isothermal melt crystallization.

Shi et al. ${ }^{[79]}$ studied the non-isothermal crystallization kinetics of $\mathrm{CaO}-\mathrm{Al}_{2} \mathrm{O}_{3}-\mathrm{CaF}_{2}-\left(\mathrm{SiO}_{2}\right)$-based mold fluxes consisting of varying amounts of $\mathrm{SiO}_{2}$ using a DSC. Their experimental work consisted of heating the mold flux above its melting point followed by continuous cooling to near the room temperature at cooling rates of $5,10,15$, and $20{ }^{\circ} \mathrm{C} \min ^{-1}$. The continuous cooling

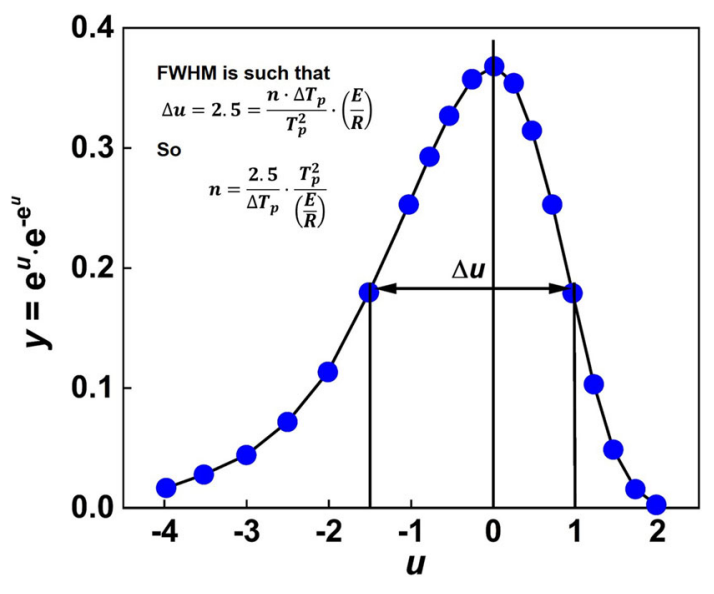

Fig. 12-The Augis-Bennett method for determining the reaction order from a DSC/DTA curve ${ }^{[77]}$ (reproduced with permission from Ref. [77]).

transformation (CCT) curves were constructed for each crystallizing phase and two main phases were observed to precipitate during cooling viz. $11 \mathrm{CaO} \cdot 7 \mathrm{Al}_{2} \mathrm{O}_{3} \cdot \mathrm{CaF}_{2}$ and $\mathrm{CaF}_{2}$. The $11 \mathrm{CaO} \cdot 7 \mathrm{Al}_{2} \mathrm{O}_{3} \mathrm{CaF}_{2}$ phase was found to precipitate first from the mold slag followed by precipitation of $\mathrm{CaF}_{2}$ at a lower temperature. Insofar the CCT diagrams are concerned, the authors reported that the crystallization start temperature for $11 \mathrm{CaO} \cdot 7 \mathrm{Al}_{2} \mathrm{O}_{3}$. $\mathrm{CaF}_{2}$ decreased with increasing amount of $\mathrm{SiO}_{2}$ in the slag and contended that the reduction in $\mathrm{CaO}$ activity in the slag due to $\mathrm{SiO}_{2}$ addition may be a possible reason for this phenomenon. They also reported that the crystallization of $\mathrm{CaF}_{2}$ starts at a higher temperature in $\mathrm{SiO}_{2}$-free slag and this observation was explained from the viewpoint of depolymerization tendency of the melt. The presence of $\mathrm{SiO}_{2}$ in the slag was found to decrease the depolymerization tendency of the melt as evident from the increase in $\mathrm{NBO} / \mathrm{T}$ values calculated by the authors using their slag compositions. In other words, the presence of $\mathrm{SiO}_{2}$ was found to increase the diffusion resistance of slag components and the energy barrier for crystallization and therefore higher temperatures were required for crystallization to take place. However, no information was provided by these authors in terms of the modes of nucleation and growth for the individual crystallization events. In addition, the construction of CCT diagrams using DSC suffers from the limitation that only a limited range of cooling rates can be used. Therefore, while this study by Shi et al. ${ }^{[79]}$ provides useful information on the crystallization kinetics in $\mathrm{CaO}-\mathrm{Al}_{2} \mathrm{O}_{3}-\mathrm{CaF}_{2}-\left(\mathrm{SiO}_{2}\right)$-based mold fluxes, its applicability to industrial casting processes may be limited because of the much higher cooling rates experienced in such processes.

Wang et al. ${ }^{[80]}$ studied the crystallization kinetics of $\mathrm{CaO}-\mathrm{SiO}_{2}-\mathrm{CaF}_{2}-\mathrm{Al}_{2} \mathrm{O}_{3}$-based mold fluxes using the Matushita and Sakka method ${ }^{[63-67]}$ together with the Ozawa equation. ${ }^{[69]}$ They also studied the effects of substitution of $\mathrm{SiO}_{2}$ in the mold flux by $\mathrm{TiO}_{2}$. They observed that cuspidine was the only phase to crystallize in $\mathrm{TiO}_{2}$-free mold fluxes while in mold fluxes containing greater than 5 pct $\mathrm{TiO}_{2}$, the crystalline phases were 
cuspidine and $\mathrm{CaTiO}_{3}$. For both of these crystallization events, the calculated values of $n$ and $m$ were all found close to unity, thereby suggesting that for both phases, the crystallization was controlled by surface crystallization. They also reported that in $\mathrm{TiO}_{2}$-containing mold fluxes, the effective activation energy for cuspidine formation was significantly increased. Since the activation energy represented the kinetic barrier for crystallization, a larger activation energy meant that crystallization became more difficult when $\mathrm{SiO}_{2}$ in the slag was substituted by an equivalent amount of $\mathrm{TiO}_{2}$. Therefore, this study contended the fact that the presence of $\mathrm{TiO}_{2}$ in the slag has a negative effect on the growth of crystal and led to a slower crystallization process.

Watanabe et al. ${ }^{[81]}$ studied the effects of alkali oxide addition on the kinetics of cuspidine formation in $\mathrm{CaO}-\mathrm{SiO}_{2}-\mathrm{CaF}_{2}$-based mold fluxes using DTA. They used the Kissinger plot ${ }^{[29,60]}$ to determine the activation energy for crystallization and observed that alkali oxides such as $\mathrm{Li}_{2} \mathrm{O}, \mathrm{K}_{2} \mathrm{O}$, and $\mathrm{Na}_{2} \mathrm{O}$ enhanced the crystallization of cuspidine from the mold slag by both lowering the crystallization temperature and also by reducing the degree of polymerization of the melt. Activation energy for cuspidine crystallization was observed to decrease significantly due to the addition of alkali oxides in the mold flux, as shown in Figure 13. Also, based on the values of $n$ and $m$ calculated from their analyses, they reported that initially surface crystallization occurred in the $\mathrm{CaO}-\mathrm{SiO}_{2}-\mathrm{CaF}_{2}$ system, which later changed to bulk crystallization due to the alkali oxide addition. Among the three alkali oxides added, $\mathrm{Li}_{2} \mathrm{O}$ was most effective in enhancing the crystallization of cuspidine. However, as expected, excessive addition of any single alkali oxide in the mold flux was found to hinder the cuspidine formation because of the substitution of $\mathrm{CaF}_{2}$ by the alkali oxide.

Choi et al. ${ }^{[82]}$ examined the non-isothermal crystallization behavior of $\mathrm{F}$-free mold flux in the system $\mathrm{CaO}-\mathrm{SiO}_{2}-\mathrm{Al}_{2} \mathrm{O}_{3}-\mathrm{Na}_{2} \mathrm{O}-\mathrm{B}_{2} \mathrm{O}_{3}$ using DTA. In a mold flux of basicity $\mathrm{CaO} / \mathrm{SiO}_{2}=1.7$, they observed the formation of $\mathrm{CaB}_{2} \mathrm{SiO}_{7}$ and $\mathrm{CaAl}_{4} \mathrm{~B}_{2}\left[\mathrm{SiO}_{4}\right]_{8}$ as the only crystalline phases in the mold slag. The order of the crystallization reaction was analyzed using the Ozawa method ${ }^{[69]}$ and the activation energy for crystallization was calculated using the Kissinger method ${ }^{[29,60]}$ and the Matushita and Sakka method. ${ }^{[63-67]}$ Using these two methods, the calculated activation energies for crystallization were found to be significantly different. This difference, as discussed by the authors, was because of the fact that the crystallization degree was greater than one and bulk nucleation with diffusion controlled one-dimensional crystal growth was found to take place. Evidently, in such a case, the Kissinger plot $\left.{ }^{[29}, 60\right]$ would result in incorrect values of activation energy as already discussed and the method of Matushita and Sakka ${ }^{[63-67]}$ should be preferred. It is, however, not clear why the Kissinger method ${ }^{[29,}{ }^{60]}$ was at all used to calculate the activation energy, even for the sake of comparing the values with those obtained from the Matushita and Sakka method ${ }^{[63-67]}$ because it is well known that in its

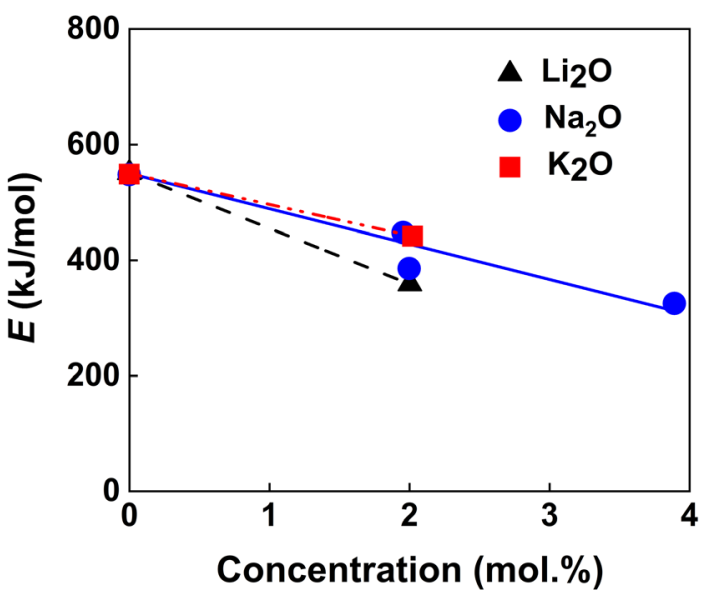

Fig. 13-Effects of alkali oxide additions on the non-isothermal crystallization kinetics of a $\mathrm{CaO}-\mathrm{SiO}_{2}-\mathrm{CaF}_{2}$-based mold flux as reported by Watanabe et al. ${ }^{[81]}$ (reproduced with permission from Watanabe et al. ${ }^{[81]}$ ).

original form, the Kissinger method ${ }^{[29,60]}$ would be not applicable in this case of mold flux crystallization during cooling.

Shu et al. ${ }^{[83]}$ also studied the non-isothermal crystallization kinetics of fluorine-free mold slags based on the $\mathrm{CaO}-\mathrm{Al}_{2} \mathrm{O}_{3}-\mathrm{B}_{2} \mathrm{O}_{3}$ using DSC. The primary crystallization phases were $\mathrm{Ca}_{3} \mathrm{Al}_{2} \mathrm{O}_{6}, \mathrm{LiAl}_{2} \mathrm{O}_{4}$ and $\mathrm{Ca}_{3} \mathrm{~B}_{2} \mathrm{O}_{6}$ and the first phase to crystallize was $\mathrm{Ca}_{3} \mathrm{Al}_{2} \mathrm{O}_{6}$. Using a modified Avrami analysis, they reported that the Avrami parameter $n$ is close to 4 for mold fluxes having $\mathrm{CaO} / \mathrm{Al}_{2} \mathrm{O}_{3}$ in the range 1 to 1.2 indicating continuous bulk nucleation and $3 \mathrm{D}$ crystal growth were the dominant mechanisms. For $\mathrm{CaO} / \mathrm{Al}_{2} \mathrm{O}_{3}$ ratio lower than one, the Avrami parameter $n$ was found to be close to three, indicating instantaneous bulk nucleation and 3D crystal growth. Furthermore, using the Friedman isoconversion method, ${ }^{[76]}$ they calculated the effective activation energies for crystallization of $\mathrm{Ca}_{3} \mathrm{Al}_{2} \mathrm{O}_{6}$ in all the mold fluxes studied and reported negative values of activation energy, which agreed well with the observations of Seo et al. ${ }^{[38]}$ in earlier investigation with conventional $\mathrm{CaO}-\mathrm{SiO}_{2}-\mathrm{CaF}_{2}$-based mold fluxes.

In a later study, Shu et al. ${ }^{[84]}$ studied the non-isothermal crystallization kinetics of $\mathrm{F}$-free mold fluxes based on the $\mathrm{CaO}-\mathrm{Al}_{2} \mathrm{O}_{3}-\mathrm{B}_{2} \mathrm{O}_{3}-\mathrm{Na}_{2} \mathrm{O}-\mathrm{Li}_{2} \mathrm{O}$ system using DSC. In this system, however, $\mathrm{Ca}_{12} \mathrm{Al}_{14} \mathrm{O}_{33}$ was found to be the first phase to precipitate followed by $\mathrm{CaO}$. For $\mathrm{Ca}_{12} \mathrm{Al}_{14} \mathrm{O}_{33}$, which precipitated as a plate-like $2 \mathrm{D}$ crystal, the use of the model proposed by Matushita and Sakka model ${ }^{[63-67]}$ was found to be satisfactory. For $\mathrm{CaO}$, the growth was either $2 \mathrm{D}$ or $3 \mathrm{D}$ depending on the $\mathrm{CaO} / \mathrm{Al}_{2} \mathrm{O}_{3}$ ratio and in this case, too, the use of Matushita and Sakka method ${ }^{[63-67]}$ was found reasonable. According to the authors, the most important crystallization event was the precipitation of $\mathrm{Ca}_{12} \mathrm{Al}_{14} \mathrm{O}_{33}$ and the effective activation energy for crystallization was found to decrease with increasing $\mathrm{CaO} / \mathrm{Al}_{2} \mathrm{O}_{3}$ ratio. Based on this observation, the authors contended that crystallization in mold fluxes during heating is enhanced with increasing $\mathrm{CaO} / \mathrm{Al}_{2} \mathrm{O}_{3}$ ratio for the same amounts of $\mathrm{B}_{2} \mathrm{O}_{3}, \mathrm{Na}_{2} \mathrm{O}$, and $\mathrm{Li}_{2} \mathrm{O} \cdot{ }^{[84]}$ 
In the preceding section, an overview of the investigations available in the literature on non-isothermal crystallization behavior using DSC/DTA has been presented. First, the different methods, which are used in the analyses of non-isothermal crystallization of glass systems, in general, have been discussed. It has been argued that the well-known Kissinger equation ${ }^{[29,60]}$ and Matushita and Sakka equations ${ }^{[63-67]}$ should be avoided for studying crystallization behavior in mold fluxes because in the case of mold fluxes, the crystallization occurs during cooling while these equations are derived for the case of crystallization during heating. The use of Ozawa equation ${ }^{[69]}$ in studying the non-isothermal crystallization behavior of $\mathrm{CaO}-\mathrm{SiO}_{2}-$ $\mathrm{CaF}_{2}$-based mold fluxes has also been found to be unsatisfactory, as reported by Seo et al. ${ }^{[78]}$ Among the other well-known methods, the Freeman and Carroll ${ }^{[70]}$ method assumes a particular functional form for the rate of crystallization. The method of Borchardt and Piloyan, ${ }^{[7,74]}$ on the other hand, suffers from an inherent limitation because of the incorrect assumption that the kinetic parameter, ct $(=\mathrm{E} / \mathrm{RT})$, is independent of temperature which, as already discussed, is not valid for most crystallization events. Therefore, neither of these methods should be used for studying the non-isothermal crystallization behavior of mold fluxes using DSC/DTA. The most satisfactory methods for studying the crystallization kinetics of mold fluxes under non-isothermal conditions are therefore the isoconverisonal method of Friedman ${ }^{[76]}$ and the Augis-Bennett method. ${ }^{[77]}$ Both of these methods are suitable for studying crystallization that occur during cooling and are based on sound mathematical bases without the use of any unwarranted assumptions.

Insofar, the individual studies on non-isothermal crystallization in mold fluxes are concerned, Seo et $a l .{ }^{[78]}$ determined the effective activation energy of cuspidine formation using the isoconverisonal method of Friedman ${ }^{[76]}$ and obtained a negative activation energy, which indicated that the crystallization phenomenon was controlled by the thermodynamic driving force for nucleation. Shi et al. ${ }^{[79]}$ studied the non-isothermal crystallization kinetics of $\mathrm{CaO}-\mathrm{Al}_{2} \mathrm{O}_{3}-$ $\mathrm{CaF}_{2}-\left(\mathrm{SiO}_{2}\right)$ and constructed CCT diagrams using DSC for cooling rates in the range 5 to $20^{\circ} \mathrm{C} \mathrm{min}{ }^{-1}$. Such CCT diagrams, however, have little relevance to the actual casting process where cooling rates in the mold are expected to be much higher. Wang et al. ${ }^{[80]}$ applied the Matushita and Sakka ${ }^{[63-67]}$ equation together with the Ozawa equation ${ }^{[69]}$ and reported several important results on the effects of $\mathrm{SiO}_{2}$ substitution in the mold fluxes by $\mathrm{TiO}_{2}$. However, their quantitative analyses related to the calculation of activation energy and the Avrami exponent $(n)$ may have entailed some errors because of the use of Matushita and Sakka ${ }^{[63-67]}$ equation which, as discussed, should not be ideally used for studying mold flux crystallization. Watanabe et al. ${ }^{[81]}$ studied the effects of alkali oxide addition on the kinetics of crystallization in $\mathrm{CaO}-\mathrm{SiO}_{2}-\mathrm{CaF}_{2}$-based mold fluxes using DTA and reported that alkali oxides such as $\mathrm{Li}_{2} \mathrm{O}$, $\mathrm{K}_{2} \mathrm{O}$, and $\mathrm{Na}_{2} \mathrm{O}$ enhanced cuspidine crystallization. Choi et al. ${ }^{[82]^{\top}}$ and Shu et al. ${ }^{[83,84]}$ examined the non-isothermal crystallization behavior of F-free mold fluxes using thermoanalytical methods. While Choi et al. ${ }^{[82]}$ used the Matushita and Sakka ${ }^{[63-67]}$ equation, Shu et al. ${ }^{[83,84]}$ used the Friedman method ${ }^{[76]}$ and therefore the numerical accuracy of the results reported by Shu et al. ${ }^{[83,84]}$ may be higher for reasons already discussed. In F-free fluxes, these authors reported that calcium aluminate phases such as $\mathrm{Ca}_{12} \mathrm{Al}_{14} \mathrm{O}_{33}$ precipitated first followed by precipitation of $\mathrm{CaO}$ and the effective activation energy for crystallization decreased with increasing $\mathrm{CaO} / \mathrm{Al}_{2} \mathrm{O}_{3}$ ratio. Therefore, they argued that crystallization in mold fluxes is enhanced with increasing $\mathrm{CaO} / \mathrm{Al}_{2} \mathrm{O}_{3}$ ratio for the same amounts of $\mathrm{B}_{2} \mathrm{O}_{3}, \mathrm{Na}_{2} \mathrm{O}$, and $\mathrm{Li}_{2} \mathrm{O} \cdot{ }^{[84]}$ Yang et al. ${ }^{[85]}$ investigated the non-isothermal crystallization behavior of a $\mathrm{CaO}$ $\mathrm{Al}_{2} \mathrm{O}_{3}$-based mold flux used for casting high-Al steel using a DSC. They also studied the effect of $\mathrm{Li}_{2} \mathrm{O}$ on the crystallization kinetics of these mold fluxes and reported that the addition of $\mathrm{Li}_{2} \mathrm{O}$ decreased the rate of crystallization in these fluxes for fixed amount of $\mathrm{Na}_{2} \mathrm{O}$. They used the Ozawa model ${ }^{[69]}$ to analyze their data on non-isothermal crystallization and their values of Avrami exponent $(n)$ indicated that volume nucleation with either a two-dimensional or three-dimensional growth is the main mechanism of nucleation and growth. More importantly, they reported even without $\mathrm{Na}_{2} \mathrm{O}$, these fluxes would have the required crystallization ability if sufficient amount of $\mathrm{Li}_{2} \mathrm{O}(\sim 6.5 \mathrm{wt}$ pct $)$ is present in these fluxes. Thus, in summary, it can be concluded that several useful information is available from the non-isothermal crystallization studies using DSC/DTA for conventional, F-free, and the newly proposed $\mathrm{CaO}-\mathrm{Al}_{2} \mathrm{O}_{3}$-based mold fluxes.

\section{B. Single and double hot thermocouple technique (SHTT and DHTT)}

In a previous section, the articles on the isothermal crystallization kinetics of mold fluxes using SHTT and DHTT have been reviewed. The SHTT and DHTT can also be used for studying the non-isothermal crystallization for mold fluxes. The basic principle remains the same but in this case, the mold slag around one thermocouple or between two thermocouples is continuously cooled at specified cooling rates, the crystallization is observed and the CCT diagrams are constructed.

Orrling et al. ${ }^{[39,86]}$ studied the non-isothermal crystallization kinetics of $\mathrm{CaO}-\mathrm{SiO}_{2}-\mathrm{Al}_{2} \mathrm{O}_{3}-\mathrm{Na}_{2} \mathrm{O}-\mathrm{CaF}_{2}$-based industrial mold fluxes using the DHTT technique. They constructed the CCT diagrams for the onset of crystallization for the mold fluxes and compared them with the TTT diagrams obtained from the isothermal crystallization studies. As expected, they reported that the time and temperature for the beginning of crystallization decreased with increasing cooling rates and for cooling rates greater than $20^{\circ} \mathrm{C} \mathrm{s}^{-1}$, no crystallization was observed indicating that the critical cooling rate for these mold slags was reached. In addition, they observed that the onset of crystallization occurred at a longer time for the continuous cooling experiments as compared to their isothermal holding experiments. This is because during continuous cooling, when the cooling curve 


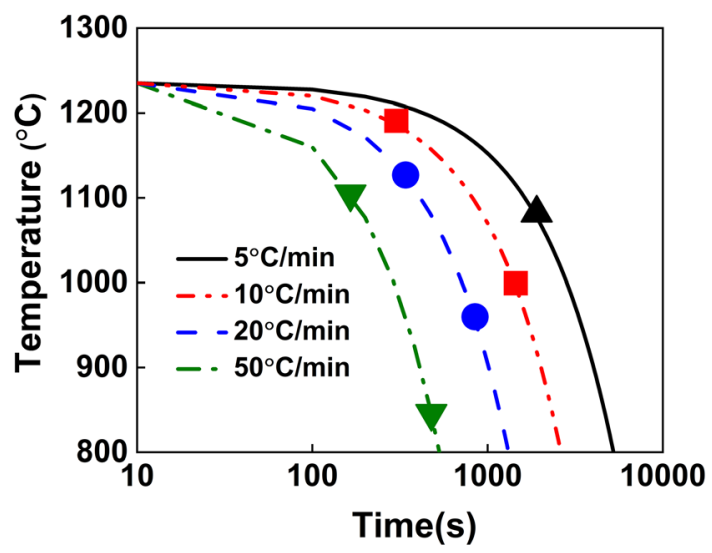

Fig. $14-\mathrm{CCT}$ diagram of a $\mathrm{CaO}-\mathrm{SiO}_{2}-\mathrm{Na}_{2} \mathrm{O}-\mathrm{Al}_{2} \mathrm{O}_{3}-\mathrm{CaF}_{2}$-based mold flux as obtained by Kölbl et al. ${ }^{[87]}$ using the SHTT (reproduced with permission from Kölbl et al. ${ }^{[87]}$ ).

reached the TTT curve, the rate of nucleation is low and therefore further time and cooling were required before the first crystal could be observed.

Kölbl et al. ${ }^{[87]}$ used the SHTT to construct the CCT diagram for an industrial mold flux based on the $\mathrm{CaO}-\mathrm{SiO}_{2}-\mathrm{Na}_{2} \mathrm{O}-\mathrm{Al}_{2} \mathrm{O}_{3}-\mathrm{CaF}_{2}$ system, as shown in Figure 14. Similar to Orrling et al., ${ }^{[39,86]}$ they also compared the CCT diagram with the TTT diagram for the same mold slag system and observed a higher degree of crystallinity in continuous cooling experiments. As explained by the authors, this was because of the fact that at least for moderate cooling rates, crystallization took place at higher temperatures mainly in the vicinity where the growth rate is maximum after nucleation occurred at the interface. Hence, the conditions for total crystallization were more favorable for continuous cooling experiments. In addition, during all continuous cooling experiments, only the crystallization of dendrites were observed by Kölbl et al. ${ }^{[87]}$ and these dendrites were finer in the case of lower cooling rates.

Zhou et al. ${ }^{[88]}$ investigated the non-isothermal crystallization kinetics of $\mathrm{CaO}-\mathrm{SiO}_{2}-$ and $\mathrm{CaO}-\mathrm{Al}_{2} \mathrm{O}_{3}$-based mold fluxes for casting high-Al steels using the SHTT. Their results showed that the crystallization ability of a $\mathrm{CaO}-\mathrm{SiO}_{2}$-based mold flux (with a basicity of $\sim 0.62$ and $\mathrm{Al}_{2} \mathrm{O}_{3}$ content $\sim 2 \mathrm{wt}$ pct) is weaker than that of a $\mathrm{CaO}-\mathrm{Al}_{2} \mathrm{O}_{3}$-based flux (with a basicity of $\sim 4.1$ and $\mathrm{Al}_{2} \mathrm{O}_{3}$ content of $\sim 32 \mathrm{wt}$ pct) because of its higher initial crystallization temperature. The crystallization kinetics of the $\mathrm{CaO}-\mathrm{SiO}_{2}$-based flux was found to be surface nucleation and growth with interface reaction control while for the $\mathrm{CaO}-\mathrm{Al}_{2} \mathrm{O}_{3}$-based flux, it was constant nucleation rate, one-dimensional growth, and diffusion control in the initial stages of crystallization, which then transformed into a constant nucleation rate, three-dimensional growth, and interface reaction control in the later stages. As discussed by the authors, this variation in the crystallization kinetics for the $\mathrm{CaO}-\mathrm{Al}_{2} \mathrm{O}_{3}$-based flux was due to the difference in the composition of the crystals precipitating in the primary and secondary crystallization stages. ${ }^{[88]}$
Lu et al. ${ }^{[89]}$ also studied the non-isothermal crystallization kinetics of $\mathrm{CaO}-\mathrm{Al}_{2} \mathrm{O}_{3}$ mold fluxes using the SHTT and DHTT with an emphasis on the effects of $\mathrm{Li}_{2} \mathrm{O}$ and $\mathrm{Na}_{2} \mathrm{O}$ additions on the crystallization behavior of these mold fluxes. Their results showed that the behavior of $\mathrm{Li}_{2} \mathrm{O}$ and $\mathrm{Na}_{2} \mathrm{O}$ in these newer mold flux systems is different to that in the conventional $\mathrm{CaO}-\mathrm{SiO}_{2}$ based fluxes. In the $\mathrm{CaO}-\mathrm{Al}_{2} \mathrm{O}_{3}$ mold flux system, the presence of either of these components below a certain critical value inhibited crystallization by lowering the initial crystallization temperature and increasing incubation time particularly in the high-temperature region. However, when the amounts of these components exceeded the critical values, the crystallization kinetics at lower temperature were significantly enhanced by the formation of new phases such as $\mathrm{LiAlO}_{2}$ and $\mathrm{Na}_{x} \mathrm{Al}_{y} \mathrm{Si}_{z} \mathrm{O}_{4}$.

In a recent study, Zhou et al. ${ }^{[90]}$ constructed the continuous heating transformation (CHT) diagram using the SHTT. This work was motivated by some earlier modeling studies by the same authors ${ }^{[91,92]}$ in which they observed dynamic evolution of mold flux crystallization by using DHTT under a simulated temperature field. In these modeling studies ${ }^{[91,92]}$, the authors followed a partial molar approach to calculate the surface tension of the mold slag ${ }^{[93]}$ and performed a force balance on the slag film to show that the deformation of the mold slag sample due to gravity could be neglected for all practical purposes. They observed that crystals were initially formed in the middle of slag film and grew towards both the low- and high-temperature sides. Under such a situation, the crystalline layer of slag film in the gap between the shell and mold is expected to develop from both liquid and glassy layers. In the liquid mold flux, the crystals tend to precipitate during cooling. However, in the glassy layer, the precipitation of crystals occurs due to the increase in interface thermal resistance resulting from the shrinkage of the solidified shell. Therefore, Zhou et al. ${ }^{[90]}$ studied the crystallization behavior in the glassy layer under non-isothermal conditions by studying the transformations that occur under continuous heating and hence constructed a CHT diagram. Two different mold fluxes were used in their study viz. a conventional low basicity $\mathrm{CaO}-\mathrm{SiO}_{2}$-based mold flux and a newly developed $\mathrm{CaO}-\mathrm{Al}_{2} \mathrm{O}_{3}$-based mold flux containing $\sim 32 \mathrm{wt}$ pct $\mathrm{Al}_{2} \mathrm{O}_{3}$. They reported from the CHT diagrams for both fluxes that the crystallization start temperature increased with increase in heating rate and attributed this to the fact that the driving force for crystallization reduces faster when the heating rate increased. In addition, they also reported that at the same heating rate the $\mathrm{CaO}-\mathrm{SiO}_{2}$-based mold flux had a lower crystallization start temperature as compared to the $\mathrm{CaO}-\mathrm{Al}_{2} \mathrm{O}_{3}$-based flux. This observation was explained by the authors in terms of the slag structure and they argued that the structural unit in the $\mathrm{CaO}-\mathrm{SiO}_{2}$ mold flux consisted only of $\left[\mathrm{SiO}_{4}\right]^{4-}$ tetrahedra while in the case of $\mathrm{CaO}-\mathrm{Al}_{2} \mathrm{O}_{3}$, it consisted of a mixture of $\left[\mathrm{SiO}_{4}\right]^{4-}$ and $\left[\mathrm{AlO}_{4}\right]^{5-}$ tetrahedra along with the $\left[\mathrm{AlO}_{6}\right]^{9-}$ octahedra. Therefore, the structural unit of $\mathrm{CaO}-\mathrm{SiO}_{2}$ mold flux was simpler which made agglomeration and formation of clusters easier, 


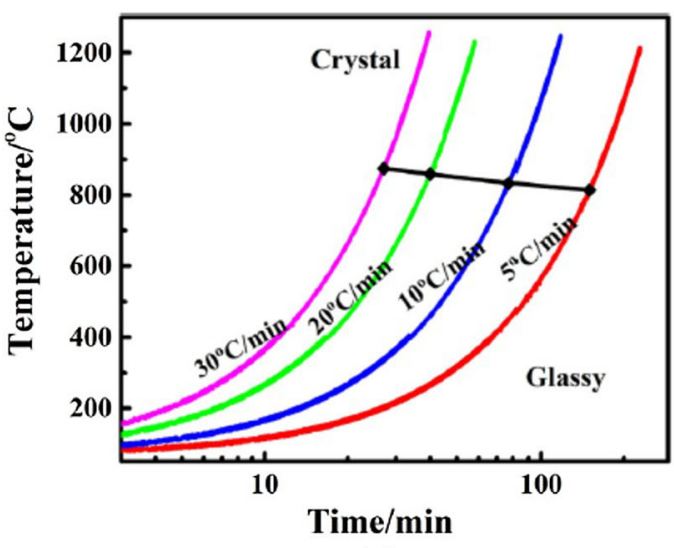

(a)

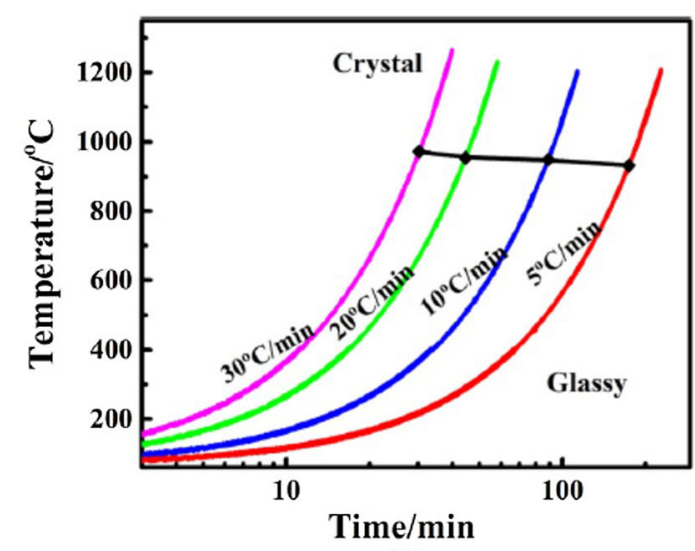

(b)

Fig. 15- CHT diagrams for two mold fluxes as reported by Zhou et al. ${ }^{[90]}$ using the SHTT - (a) a conventional CaO-SiO${ }_{2}$-based mold flux and (b) a newly developed $\mathrm{CaO}-\mathrm{Al}_{2} \mathrm{O}_{3}$-based mold flux containing 32 wt pet $\mathrm{Al}_{2} \mathrm{O}_{3}$ (reproduced with permission from $\mathrm{Zhou} \mathrm{et} \mathrm{al.}{ }^{[90]}$ ).

thereby facilitating nucleation at lower temperature. Figure 15 shows the two CHT diagrams, as reported by Zhou et al. ${ }^{[90]}$ _one for the conventional low basicity $\mathrm{CaO}-\mathrm{SiO}_{2}$-based mold flux and the other for the newly developed $\mathrm{CaO}-\mathrm{Al}_{2} \mathrm{O}_{3}$-based mold flux.

As already discussed, the DHTT has the unique advantage in that a temperature gradient can be applied between the two thermocouples and therefore it is possible to generate different thermal gradients as encountered in the actual continuous casting process. Thus, apart from the usual non-isothermal cooling experiments, the DHTT is also used to simulate the near-service conditions as encountered in an actual continuous casting process. The molten slag is stretched between two thermocouples, and one side is quenched at a temperature representing the mold side, while the other is either held or cooled at a particular cooling rate simulating the cooling of the steel side. Some investigators ${ }^{[94,95]}$ studied the effect of water vapor on crystallization behavior of mold slags using the DHTT method. Another recent application of the DHTT has been to study the effect of bubble formation during the crystallization in mold slags. Gu et al. ${ }^{[96]}$ studied the effect of bubble formation on the non-isothermal crystallization behavior of $\mathrm{CaO}-\mathrm{SiO}_{2}$-based mold fluxes. They observed that crystallization tendency of mold fluxes was enhanced by adding bubbles because it shortened the incubation time of crystallization and increased the critical cooling rate. As a result, the fraction of the crystalline phase in the slag film increased but the nature of the crystalline phase was not effected by bubble formation. Cuspidine remained as the primary crystalline phase in the slag film both with and without bubble formation. Furthermore, they also reported that with an increase in bubble content, the growth mechanism of the cuspidine changed from a low dimension to a high dimension and the activation energy for crystallization decreased. ${ }^{[96]}$

In the foregoing section, a summary of the investigations on non-isothermal crystallization kinetics using the SHTT and DHTT has been presented. As in the case of isothermal crystallization kinetics, the SHTT and the
DHTT can also be used in the study of non-isothermal crystallization kinetics. Orrling et al. ${ }^{[39,86]}$ studied the non-isothermal crystallization kinetics of $\mathrm{CaO}-\mathrm{SiO}_{2}-\mathrm{A}$ $\mathrm{l}_{2} \mathrm{O}_{3}-\mathrm{Na}_{2} \mathrm{O}-\mathrm{CaF}_{2}$ mold fluxes using DHTT technique and noticed that the crystallization started at a longer time in continuous cooling experiments as compared to isothermal experiments. Similarly, Kölbl et al. ${ }^{[87]}$ constructed the CCT diagrams for an industrial mold flux using SHTT. They observed a higher degree of crystallinity in continuous cooling experiments and thus concluded that the conditions for total crystallization were more favorable in continuous cooling experiments. In a very recent and novel study, Zhou et al. ${ }^{[90]}$ used the SHTT to construct what they referred to as the continuous heating transformation (CHT) diagram in order to simulate the conditions of growth of the crystals in the glassy layer of the mold slag. They observed from their CHT diagrams that the crystallization start temperature increased with increase in heating rate and reported that in $\mathrm{CaO}-\mathrm{SiO}_{2}$-based mold fluxes started to crystallize at a lower temperature as compared to $\mathrm{CaO}-\mathrm{Al}_{2} \mathrm{O}_{3}$-based fluxes. It is, therefore, evident that several aspects of crystallization kinetics in $\mathrm{CaO}-\mathrm{SiO}_{2}$ based and $\mathrm{CaO}-\mathrm{Al}_{2} \mathrm{O}_{3}$-based fluxes are available from the reported studied on non-isothermal crystallization kinetics using the SHTT and DHTT. In addition, the DHTT has been recently used to simulate near-service conditions as seen in an actual continuous casting process, as already mentioned. Out of these studies, the investigation of $\mathrm{Gu}$ et al. ${ }^{[96]}$ on the use of DHTT to study the effect of bubble formation on the crystallization phenomena in of $\mathrm{CaO}-\mathrm{SiO}_{2}-\mathrm{CaF}_{2}$-based mold fluxes deserves special mention.

\section{Confocal scanning laser microscopy (CSLM)}

In an earlier section, the studies on isothermal crystallization kinetics of mold fluxes using CSLM have been reviewed. In this section, a review on the non-isothermal crystallization kinetics using CSLM will be presented. 


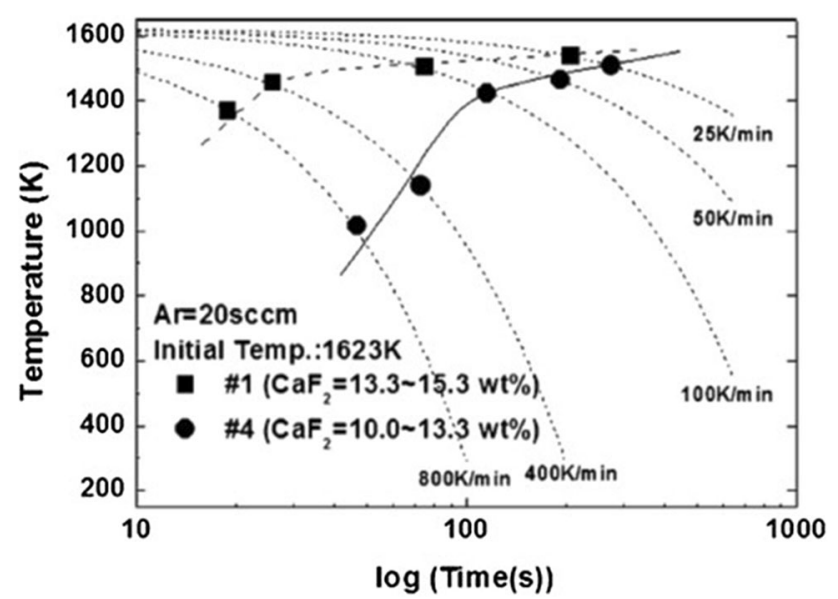

Fig. 16-CCT curves of two $\mathrm{CaO}-\mathrm{SiO}_{2}-\mathrm{Al}_{2} \mathrm{O}_{3}-\mathrm{Na}_{2} \mathrm{O}-\mathrm{CaF}_{2}-\mathrm{NaF}-$ based mold fluxes with varying $\mathrm{CaF}_{2}$ concentrations as obtained by Parl et al..$^{[97]}$ using a CSLM (reproduced with permission from Park et al. ${ }^{[97]}$.

Park et al. ${ }^{[97]}$ studied the crystallization behavior of highly volatile $\mathrm{CaO}-\mathrm{SiO}_{2}-\mathrm{Al}_{2} \mathrm{O}_{3}-\mathrm{Na}_{2} \mathrm{O}-\mathrm{CaF}_{2}-\mathrm{NaF}$-based mold fluxes using a CSLM. They used an isolated observation chamber using a quartz cover for their in situ observation because of which slightly blurred images of cuspidine crystals were observed. Nevertheless, the phase could be identified using SEM and XRD analyses. They constructed the CCT curves for all the four different mold fluxes studied in their work by using cooling rates in the range 25 to $800{ }^{\circ} \mathrm{C} \mathrm{min}^{-1}$, as shown in Figure 16. These CCT diagrams clearly indicated that higher basicity in the mold flux enhanced the crystallization of cuspidine. This can be attributed to the presence of excess $\mathrm{O}_{2}$, i.e., free oxygen in higher basicity slags which resulted in depolymerization of the silica melt and a decrease in the viscosity, which in turn improved the rate of diffusion of the ionic species necessary for the crystallization process. In addition, they also reported that $\mathrm{CaF}_{2}$ and $\mathrm{NaF}$ might have similar effects of depolymerizing the slag network thus improving the kinetics of crystallization. This improved kinetics would further enhance the formation of cuspidine during cooling.

Hanao ${ }^{[98]}$ studied the crystallization kinetics in a $\mathrm{CaO}-\mathrm{SiO}_{2}-\mathrm{CaF}_{2}-\mathrm{NaF}$ mold flux using a CSLM. He also constructed the CCT diagram from the observed images and compared the CCT diagrams for two different mold fluxes studied with varying compositions. Hanao ${ }^{[98]}$ also observed that the crystallization rate of cuspidine increased with the basicity of the mold flux. However, the dependency of crystallization on the cooling rate was different for mold fluxes of different basicity. This difference, as explained by the author, could be due to the difference in the viscosity of mold fluxes at the crystallization temperature. Therefore, Hanao ${ }^{[98]}$ contended that crystallization rate is also related to the viscosity of the mold slag at the crystallization temperature because it controls the diffusion of the ions required for the formation of the crystalline phase, i.e., cuspidine. Cho and Shibata ${ }^{[99]}$ also studied the crystallization behavior of mold fluxes with varying basicity using CSLM and likewise observed that the rate of crystallization of cuspidine is higher in mold fluxes of higher basicity.

$\mathrm{Li}$ et al. ${ }^{[100]}$ studied the effects of cooling rate on the crystallization behavior of a new type of $\mathrm{CaO}-\mathrm{Al}_{2} \mathrm{O}_{3}$ $\mathrm{B}_{2} \mathrm{O}_{3}-\mathrm{CaF}_{2}$-based mold flux, which is used for casting high-Al steel grades using CSLM. The two main crystalline phases in this mold slag were $\mathrm{Ca}_{3} \mathrm{~B}_{2} \mathrm{O}_{6}$ and $\mathrm{Ca}_{12} \mathrm{Al}_{14} \mathrm{O}_{33}$. The morphology of the $\mathrm{Ca}_{12} \mathrm{Al}_{14} \mathrm{O}_{33}$ was observed to gradually change from an irregular massive block shape to a faceted shape with an increase in cooling rate. Similarly, the morphology of $\mathrm{Ca}_{3} \mathrm{~B}_{2} \mathrm{O}_{6}$ was also seen to change from a large dendritic shape to a small faceted shape with increasing cooling rate. The primary crystalline phase was $\mathrm{Ca}_{12} \mathrm{Al}_{14} \mathrm{O}_{33}$ and it showed four different morphologies at cooling rates ranging from 1 to $800{ }^{\circ} \mathrm{C} \mathrm{min}^{-1} \mathrm{viz}$. faceted shape, block-shape with fine stripes, large sheet with cloudy dendrites, and dendrites. The crystallization temperature of $\mathrm{Ca}_{12} \mathrm{Al}_{14} \mathrm{O}_{33}$, as reported by the authors, decreased from $1177{ }^{\circ} \mathrm{C}$ to $894{ }^{\circ} \mathrm{C}$ as the cooling rate increased from 30 to $500{ }^{\circ} \mathrm{C} \mathrm{min}^{-1}$ and the crystallization mechanism of $\mathrm{Ca}_{12} \mathrm{Al}_{14} \mathrm{O}_{33}$ was deduced to be surface crystallization.

Jung et al. ${ }^{[101]}$ studied the effect of $\mathrm{Al}_{2} \mathrm{O}_{3}$ on the crystallization and viscosity of $\mathrm{CaO}-\mathrm{SiO}_{2}-\mathrm{CaF}_{2}$-based mold fluxes. They reported that $\mathrm{Al}_{2} \mathrm{O}_{3}$ additions lowered the crystallization temperature and in high $\mathrm{Al}_{2} \mathrm{O}_{3}$-containing fluxes, fewer crystalline phases were formed. At low cooling rates, dendrites were seen to have formed within the crystalline phases whereas at faster cooling rates the dendrites did not form and a spherical morphology was observed. Furthermore, they contended that the substitution of $\mathrm{SiO}_{2}$ with $\mathrm{Al}_{2} \mathrm{O}_{3}$ in the mold flux modified the dominant silicate network into complex alumino-silicates, which was confirmed using FTIR and Raman spectroscopy analyses.

In this section, the available investigations on the non-isothermal crystallization behavior of mold fluxes using CSLM have been reviewed. In the CSLM, often the crystallization phenomena of mold fluxes is observed in an isolated chamber as done by Park et al. ${ }^{[97]}$ They constructed CCT curves for cooling rates of practical importance to continuous casting and reported that high basicity mold fluxes show enhanced crystallization, as expected. Hanao ${ }^{[98]}$ and Cho and Shibata ${ }^{[99]}$ also made similar observations. In recent works, $\mathrm{Li}$ et al.$^{[100]}$ and Jung et al..$^{[101]}$ studied crystallization behavior of $\mathrm{Al}_{2} \mathrm{O}_{3}$-containing mold fluxes using the CSLM. Li et al. ${ }^{[100]}$ reported that the major crystalline phases in a $\mathrm{CaO}-\mathrm{Al}_{2} \mathrm{O}_{3}-\mathrm{B}_{2} \mathrm{O}_{3}-\mathrm{CaF}_{2}$-based mold flux were $\mathrm{Ca}_{3} \mathrm{~B}_{2} \mathrm{O}_{6}$ and $\mathrm{Ca}_{12} \mathrm{Al}_{14} \mathrm{O}_{33}$ and the morphology of both of these phases were reported to change with cooling rate. Jung et al. ${ }^{[101]}$, on the other hand, observed that $\mathrm{Al}_{2} \mathrm{O}_{3}$ additions lowered the crystallization temperature while in high $\mathrm{Al}_{2} \mathrm{O}_{3}$ fluxes fewer crystalline phases were formed. They also observed that at low cooling rates, dendrites formed whereas at faster cooling rates, a spherical morphology was seen. Therefore, because of its capability of achieving very high cooling rates, the CSLM has been widely used to study non-isothermal 
crystallization over a very high range of cooling rates and the effects of cooling rate on crystal morphology have been studied in these investigations. Also, the CSLM has been used in the crystallization study of non-conventional mold fluxes such as $\mathrm{Al}_{2} \mathrm{O}_{3}$-containing fluxes used in casting of TRIP steels. There is, however, little or no information available on the crystallization of F-free mold fluxes using a CSLM under non-isothermal conditions and this can be an important area of research in the imminent future.

\section{CONCLUDING REMARKS}

In the previous sections, a review of the existing literature on the crystallization kinetics of mold fluxes using the three most commonly used techniques viz. thermal analyses, SHTT and DHTT, and confocal scanning laser microscopy (CSLM) has been presented. In this section, as a concluding remark, the relative merits and demerits of these methods have been summarized.

The thermoanalytical techniques such as DSC/DTA are the most commonly used methods used in the study of crystallization kinetics in glass-forming liquids. They are, therefore, also used extensively in the crystallization studies of mold fluxes. Under isothermal conditions, the transformation kinetics can be simply expressed in terms of the well-known JMAK equation. However, under non-isothermal conditions, the data need to be treated in such a way so that the temperature dependence of the rate constant for crystallization is accounted for. Several methods are available in the literature for this treatment some of which have been discussed in this publication. It must, however, be noted that the variety of analytical methods is more a measure of the complexity of the physical problem than the mathematical problem. In other words, while choosing the appropriate method for analyzing the non-isothermal crystallization kinetics, it is important not to lose sight of the physics of the problem. In general, the most well-known among these methods is the Kissinger equation. ${ }^{[29,60]}$ However, the applicability of this method, in the case of crystallization in mold fluxes, which occur during cooling, is questionable. Similarly, the use of other well-known methods such as the ones proposed by Maushita and Sakka ${ }^{[63-67]}$. Freeman and Carroll ${ }^{[70]}$ and Borchardt and Piloyan ${ }^{[73,74]}$ should be avoided for reasons already discussed. It is suggested that either the isoconversional method of Friedman ${ }^{[76]}$ or the Augis-Bennett ${ }^{[77]}$ method be applied in the analyses of non-isothermal crystallization data for mold fluxes because these are the only two methods which would yield dependable values of the activation energy and the Avrami exponent. In addition, the method of Ozawa ${ }^{[69]}$ can be applied with proper precautions as this method is based on much fewer assumptions than some other methods discussed in this work.

An important limitation of the thermoanalytical techniques is that high cooling rates as encountered in an actual continuous casting process cannot be applied in these techniques. Often times, the maximum cooling rate that can be applied to DSC/DTA experiments are of the order of $50{ }^{\circ} \mathrm{C} \mathrm{min}{ }^{-1}$, which is significantly lower than those are relevant to the actual casting process. This limitation is particularly a problem for studying isothermal crystallization kinetics using DSC/DTA and isothermal crystallization phenomena occurring at temperatures close to the melting point can only be appropriately studied using the DSC/DTA. In case of non-isothermal crystallization, this is a lesser problem. However, in such cases, too, the crystalline phase fraction will depend on the cooling rate and therefore proper care must be taken while applying the results obtained from non-isothermal DSC/DTA experiments in the determination of crystallization behavior of mold fluxes under industrial casting conditions.

The hot thermocouple technique (SHTT and DHTT) is also an important technique used in the study of crystallization kinetics of mold fluxes. This technique has the unique advantage that the slag can be directly melted on the tip of a thermocouple or between two similarly configured thermocouples and it can therefore be used to observe the crystallization phenomena in situ. In addition, very high cooling rates as encountered in an industrial casting process can be realized with this technique. Thus, this technique offers several advantages over the more conventional thermoanalytical techniques. The DHTT also has another important application in that it can be used for studying crystallization under near-service conditions and in such applications, the DHTT gives the most detailed information including not only the crystallization temperature but also the morphology. However, this technique also suffers from some disadvantages. First, the application SHTT/ DHTT is restricted to slag systems containing low amounts of evaporating components. Moreover, the time required for data analysis is much longer than that required for thermoanalytical methods. In addition, the experimental set-up required for SHTT/DHTT is much more complicated as compared to the more conventional techniques such as the DSC/DTA. In addition, although the experiment apparatus used for the SHTT and DHTT has improved since its inception in the 1950s, some deficiencies still remain. In the way this technique is set-up, it is expected that the temperature gradient will be minimum at the cold wire. However, thermal calculations done by some authors ${ }^{[52]}$ had shown that the minimum in temperature gradient is located somewhere in the middle owing to the heat loss from the surface of the sample to the surroundings. ${ }^{[52]}$ Moreover, it has been reported that in the original U-shaped design of the thermocouples, the detection of crystals within a slag containing coloring oxides such as $\mathrm{Fe}_{2} \mathrm{O}_{3}$ is difficult. In recent investigations, Kölbl et al. ${ }^{[52]}$ have attempted to overcome these shortcomings by changing the design of the original experimental set-up for the SHTT/DHTT. Instead of two U-shaped thermocouples, these authors have used one $\mathrm{H}$-shaped heating wire and a U-shaped stretching device. Using this device, they were successful in observing the crystallization of slags containing small amounts of coloring oxides such as $\mathrm{Fe}_{2} \mathrm{O}_{3}$. Moreover, using this 
device, they were also able to shift the position of the minimum temperature to the cold wire. ${ }^{[52]}$

The other most important technique used to study crystallization kinetics of mold fluxes is the CSLM. It is a state-of-the-art facility, which has been used in crystallization studies, only very recently. The CSLM has an extra-ordinary capability to make in situ observations and similar to SHTT/DHTT, very high cooling rates can be obtained using this technique. However, this technique suffers from the disadvantage that only a small sample size can be used and the field of view for this technique is limited. The basic principle behind the confocal microscope is that it uses a spatial filtering to generate a focussed spot of illumination. Therefore, crystallization taking place from the focussed spot can only be visualized and if the crystallization occurs anywhere outside the point of focus, it will not be observed using the CSLM. In addition, the CSLM is an expensive and delicate piece of instrument and it requires some expertise to extract reliable information from the videos recorded using this technique. Some investigators have also reported that the observation of crystallization phenomena for conventional F-containing fluxes using a CSLM can be difficult because of the evaporation of $\mathrm{F}$ from the mold fluxes and have hence used an isolated quartz chamber for observing crystallization. ${ }^{[97]}$ Also, the Ar flow inside the CSLM may have some effect on the kinetics and degree of crystallization. However, as reported by Barraza et al., ${ }^{[31]}$ such effect is negligible even for significantly high values of the Ar flow rate. Despite these disadvantages, the CSLM is the most versatile and state-of-the-art technique that can be used for studying crystallization in mold fluxes.

\section{ACKNOWLEDGMENTS}

The authors would like to acknowledge the financial assistance received from the Research Fund for Coal and Steel (RFCS) under the Grant Number RFCS-2018-847269.

\section{OPEN ACCESS}

This article is licensed under a Creative Commons Attribution 4.0 International License, which permits use, sharing, adaptation, distribution and reproduction in any medium or format, as long as you give appropriate credit to the original author(s) and the source, provide a link to the Creative Commons licence, and indicate if changes were made. The images or other third party material in this article are included in the article's Creative Commons licence, unless indicated otherwise in a credit line to the material. If material is not included in the article's Creative Commons licence and your intended use is not permitted by statutory regulation or exceeds the permitted use, you will need to obtain permission directly from the copyright hold- er. To view a copy of this licence, visit http://creativec ommons.org/licenses/by/4.0/.

\section{LIST OF SYMBOLS}

$a \quad$ An exponent used in the method of Freeman and Carroll for determining the activation energy of crystallization as defined in Eq. [22] $(-)$

c A variable equal to $\frac{E \beta}{R T^{2}}$ as defined in Eq. [25] $\left(\mathrm{s}^{-1}\right)$

$f_{\text {crys }} \quad$ Fraction of crystalline phases in the slag film (-)

$f(X) \quad$ A function of crystallized volume fraction $(X)$ used to express the differential rate law for crystallization as per Eq. [5] (-)

$k \quad$ Rate constant for the crystallization process $\left(\mathrm{s}^{-1}\right)$

$m \quad$ A constant used in the Matushita and Sakka method for calculating the activation energy $(E)$ of crystallization as defined in Eq.[16] (-)

$n \quad$ Avrami exponent as defined Eq. [4] (-)

$q_{\text {hor }} \quad$ Horizontal heat flux $\left(\mathrm{W} \mathrm{m}^{-2}\right.$ )

$r$ Reaction order for the crystallization process as defined in Eq. [6]

$t \quad$ Time (s)

$u \quad$ A variable that equals $K t$ as defined in Eq. [32] $(-)$

$v \quad$ Exponent for the heating rate used in the Matushita and Sakka method for calculating the activation energy $(E)$ of crystallization as defined in Eq. [16] (-)

$A \quad$ Pre-exponential factor for $k\left(\mathrm{~s}^{-1}\right)$

$B \quad$ Proportionality constant between the rate of crystallization $(\dot{X})$ and the temperature difference $(\Delta T)$ as measured in a DTA $\left(\mathrm{K}^{-1} \mathrm{~s}^{-1}\right)$

$E \quad$ Activation energy for crystallization $\left(\mathrm{kJ} \mathrm{mol}^{-1}\right)$

$\Delta G \quad$ Gibbs' free energy associated with the nucleation of a crystallite from the liquid slag $(\mathrm{J}$ $\mathrm{mol}^{-1}$ )

$\Delta H_{t} \quad$ The change in enthalpy at any time $t$ during the crystallization process $\left(\mathrm{J} \mathrm{mol}^{-1}\right)$

$\Delta H_{t o t}$ The change in enthalpy associated with the entire crystallization process $\left(\mathrm{J} \mathrm{mol}^{-1}\right)$

$K \quad$ Rate constant in the JMAK equation as defined in Eq. [6] $\left(\mathrm{s}^{-1}\right)$

$K_{0} \quad$ Pre-exponential factor for $K\left(\mathrm{~s}^{-1}\right)$

$R \quad$ Universal gas constant $\left(\mathrm{J} \mathrm{mol}^{-1} \mathrm{~K}^{-1}\right)$

$R_{\text {eff }} \quad$ Overall thermal resistance between the steel shell and the copper mold $\left(\mathrm{K} \mathrm{W}^{-1}\right)$

$R_{i} \quad$ Thermal resistance for component $i$ in the copper mold $\left(\mathrm{K} \mathrm{W}^{-1}\right)$

$S \quad$ Shape index for the DSC normalized heat flow curve as defined in Eq. [12] (-)

$T \quad$ Temperature (K)

$T_{0} \quad$ Temperature at the beginning of the heating cycle for non-isothermal crystallization experiments $(\mathrm{K})$

$T_{p} \quad$ Crystallization peak temperature (K)

$U \quad$ Growth rate of the crystallized nuclei at any time $t\left(\mathrm{~m} \mathrm{~s}^{-1}\right)$ 
$U_{o} \quad$ Initial growth rate of the crystallized nuclei (m $\mathrm{s}^{-1}$ )

$X \quad$ Crystallized volume fraction (-)

$X_{p} \quad$ Crystallized volume fraction at the crystallization peak temperature (-)

$\dot{X} \quad \frac{d X}{d t}$, i.e., The first derivative of crystallized volume fraction with respect to time, it also denotes the rate of crystallization $\left(\mathrm{s}^{-1}\right)$

$\ddot{X} \quad \frac{d^{2} X}{d t^{2}}$, i.e., The second derivative of crystallized volume fraction with respect to time $\left(\mathrm{s}^{-2}\right)$

$\beta \quad$ Heating rate $\left(\mathrm{K} \mathrm{s}^{-1}\right)$

$\varphi(X) \quad$ A function of the crystallized volume fraction $(X)$ as defined in Eq. [29]

\section{REFERENCES}

1. K.C. Mills and C.Å. Däcker: The Casting Powders Book, Springer, Cham, 2018, pp. 4-8.

2. Z. Li, R.P. Thackray, K.C. Mills, Proc. VII Int. Conf. Molten Slags, Fluxes and Salts, Capetown, South Africa, 2004, pp. 813-19.

3. J.A. Kromhout and R.C. Schimmel: Ironmak. Steelmak., 2018, vol. 45, pp. 249-56.

4. K.C. Mills, A.B. Fox, Z. Li, and R.P. Thackray: Ironmak. Steelmak., 2005, vol. 32, pp. 26-34.

5. K.C. Mills and A.B. Fox: ISIJ Int., 2003, vol. 43, pp. 1479-86.

6. J.W. Cho, H. Shibata, T. Emi, and M. Suzuki: ISIJ Int., 1998, vol. 38 , pp. $268-75$.

7. K. Watanabe, H. Okamoto, P. Suzuki, H. Kondo, and T. Shiomi: Proc. 79th Steelmak. Conf., Warrendale, PA, 1996, p. 265.

8. H. Nakada and K. Nagata: ISIJ Int., 2006, vol. 46, pp. 441-49.

9. M. Hanao and M. Kawamoto: ISIJ Int., 2008, vol. 48, pp. 18085.

10. M. Hanao, M. Kawamoto, and A. Yamanaka: ISIJ Int., 2012, vol. 52 , pp. $1310-19$.

11. S. Riaz, K.C. Mills, N. Nagata, V. Ludlow, and A.S. Normanton: High Temp. Mater. Process., 2003, vol. 22, pp. 379-86.

12. C. Yang, G. Wen, P. Tang, and C. Xi: Powder Diffr., 2016, vol. 31 , pp. $40-51$.

13. K.C. Mills, L. Courtney, A.B. Fox, B. Harris, Z. Idoyaga, and M.J. Richardson: Thermochim. Acta, 2002, vol. 391, pp. 175-86.

14. K.C. Mills, S. Karagadde, P.D. Lee, L. Yuan, and F. Shahbazian: ISIJ Int., 2016, vol. 56, pp. 264-73.

15. M. Susa, K. Nagata, and K.C. Mills: Ironmak. Steelmak., 1993, vol. 20 , pp. $372-78$.

16. S. Ozawa, M. Susa, T. Goto, R. Endo, and K.C. Mills: ISIJ Int., 2006, vol. 46, pp. 413-19.

17. M. Hanao, M. Kawamoto, T. Tanaka, and M. Nakamoto: ISIJ Int., 2006, vol. 46, pp. 346-51.

18. Y. Kobayashi, T. Shimizu, S. Miyashita, R. Endo, and M. Susa: ISIJ Int., 2011, vol. 51, pp. 186-92.

19. Z. Elahipanah: M.Sc. Thesis, Royal Institute of Technology (KTH), 2012.

20. L. Zhou, W. Wang, and K. Zhou: Metall. Mater. Trans. E, 2015, vol. 2E, pp. 99-108.

21. L. Fedunik-Hofman, A. Bayon, and S.W. Donne: Energies, 2019, vol. 12 , pp. 2981-3015.

22. C.D. Doyle: J. Appl. Polym. Sci., 1961, vol. 5, pp. 285-92.

23. C.D. Doyle: J. Appl. Polym. Sci., 1962, vol. 6, pp. 639-42.

24. P. Murray and J. White: Trans. Br. Ceram. Soc., 1955, vol. 54, pp. 204-37.

25. A.W. Coats and J.P. Redfern: Nature, 1964, vol. 201, pp. 68-69.

26. A. Khawam and D.R. Flanagan: J. Phys. Chem., 2005, vol. 109, pp. $10073-80$.

27. M.D. Seo, C.B. Shi, J.Y. Baek, J.W. Cho, and S.H. Kim: Metall. Mater. Trans. B, 2015, vol. 46B, pp. 2374-83.

28. Y.G. Maldonado, C.D.L.P. Barraza, S.A. Rodriguez, A.H.E. Castillejos, and B.G. Thomas: Metall. Mater. Trans. B, 2015, vol. 46B, pp. 286-303.
29. H.E. Kissinger: J. Res. Natl Bur. Stand., 1956, vol. 57, pp. $217-$ 21.

30. P. Šimon: J. Therm. Anal. Calorim., 2005, vol. 82, pp. 651-57.

31. C.D.L.P. Barraza, A.H.E. Castillejos, S.A. Rodriguez, and F.C. Ortega: Metall. Mater. Trans. B, 2020, vol. 51B, pp. 732-55.

32. F. Ordway: J. Res. Natl Bur. Stand., 1952, vol. 48, pp. 152-58.

33. Y. Ohta, K. Morinaga, and T. Yanagase: Bull. Jpn Inst. Met., 1980, vol. 19, p. 139.

34. E. Asayama, H. Takebeand, and K. Morinaga: ISIJ Int., 1993, vol. 33, pp. 233-38.

35. Y. Kashiwaya, C.E. Cicutti, A.W. Cramb, and K. Ishii: ISIJ Int., 1998, vol. 38, pp. 348-56.

36. T. Kuranaga. Y. Kashiwaya, and K. Ishii: Proc. Int. Symp. Adv. Mater. Technol. 2lst Century, Honolulu, USA, 1995.

37. Y. Murayama, Y. Kashiwaya, and K. Ishii: CAMP-ISIJ, 1994, vol. 7 , p. 891.

38. D.R. Uhlman: J. Am. Ceram. Soc., 1983, vol. 66, pp. 95-100.

39. C. Orrling, S. Sridhar, and A.W. Cramb: High Temp. Mater. Process., 2001, vol. 20, pp. 195-99.

40. G. Wen, H. Lui, and P. Tang: J. Iron Steel Res. Int., 2008, vol. 15, pp. 32-37.

41. L. Zhou, W. Wang, F. Ma, J. Li, J. Wei, H. Matsuura, and F. Tsukihashi: Metall. Mater. Trans. B, 2012, vol. 43B, pp. 354-62.

42. M. Petajajarvi, J.L. Klug, P. Hooli, H.P. Heller, P.R. Scheller, Proc. IX Int. Conf. Molten Slags, Fluxes Salts, Beijing, China, 2012.

43. W. Wang, B. Lu, and D. Xiao: Metall. Mater. Trans. B, 2016, vol. 47B, pp. 384-89.

44. W. Yan, W. Chen, Y. Yang, C. Lippold, and A. Mclean: ISIJ Int., 2015, vol. 55, pp. 1000-09.

45. G. Wen, S. Sridhar, P. Tang, X. Qi, and Y. Liu: ISIJ Int., 2007, vol. 47, pp. 1117-25.

46. Q. Wang, Y.J. Lu, S.P. He, K.C. Mills, and Z. Li: Ironmak. Steelmak., 2011, vol. 38, pp. 297-301.

47. L. Zhou, W. Wang, and K. Zhou: ISIJ Int., 2015, vol. 55, pp. 1916-24.

48. J. Yang, J. Zhang, Y. Sasaki, O. Ostrovski, C. Zhang, D. Cai, and Y. Kashiwaya: Metall. Mater. Trans. B, 2016, vol. 47B, pp. $2447-58$.

49. J. Chen, W. Wang, L. Zhou, and Z. Pan: J. Iron Steel Res. Int., 2020, https://doi.org/10.1007/s42243-020-00439-4.

50. J.L. Klug, R. Hagemann, N.C. Heck, A.C.F. Vilela, H.P. Heller, and P.R. Scheller: Steel Res Int., 2013, vol. 84, pp. 344-51.

51. B. Jiang, W. Wang, I. Sohn, J. Wei, and B. Lu: Metall. Mater. Trans. B, 2014, vol. 45B, pp. 1057-67.

52. N. Kölbl, I. Marschall, and H. Harmuth: J. Iron Steel Res. Int., 2019, vol. 26, pp. 345-54.

53. I. Sohn and R. Dippenaar: Metall. Mater. Trans. B, 2016, vol. 47B, pp. 2083-94.

54. T. Emi, H. Shibata, H. Yin, Proc. Belton Meml Symp., Sydney, Australia, 2000, pp. 195-207.

55. N. Yuki, H. Shibata, and T. Emi: ISIJ Int., 1998, vol. 38, pp. $317-23$.

56. H. Yin, H. Shibata, T. Emi, and M. Suzuki: ISIJ Int., 1997, vol. 37, pp. 936-45.

57. Z.T. Zhang, G.H. Wen, J.L. Liao, and S. Sridhar: Steel Res Int., 2010 , vol. 81 , pp. $516-28$

58. H.G. Ryu, Z.T. Zhang, J.W. Cho, G.H. Wen, and S. Sridhar: ISIJ Int., 2010, vol. 50, pp. 1142-50.

59. Z.T. Zhang, J. Li, and P. Liu: J. Iron Steel Res. Int., 2011, vol. 18, pp. $31-37$.

60. H.E. Kissinger: Anal. Chem., 1957, vol. 29, pp. 1702-06.

61. S.S. Vyazovkin: Macromol. Rapid Commun., 2002, vol. 23, pp. $771-75$.

62. S. Vyazovkin: J. Comput. Chem., 1997, vol. 18, pp. 393-402.

63. K. Matusita, S. Sakka, and Y. Matsui: J. Mater. Sci., 1975, vol. 10, pp. 961-66.

64. K. Matusita and S. Sakka: Thermochim. Acta, 1979, vol. 33, pp. $351-54$

65. K. Matusita and S. Sakka: Bull. Inst. Chem. Res. Kyoto Univ., 1981, vol. 3, pp. 159-71.

66. K. Matusita, S. Sakka, and Y. Matsui: J. Non-cryst. Solids, 1980, vols. 38-39, pp. 741-46.

67. K. Matusita, S. Sakka, and Y. Matsui: J. Mater. Sci., 1984, vol. 19 , pp. 291-96. 
68. C.B. Shi, H. Wang, M.D. Seo, J.W. Cho, and S.H. Kim: Metall. Mater. Trans. B, 2014, vol. 45B, pp. 1987-91.

69. T. Ozawa: Polymer, 1971, vol. 12, pp. 150-58.

70. E.S. Freeman and B. Carroll: J. Phys. Chem., 1958, vol. 62, pp. 394-97.

71. A.A. Van Dooren and B.W. Muller: Thermochim. Acta, 1983, vol. 65 , pp. 269-84.

72. A. Jerez: J. Therm. Anal., 1983, vol. 26, pp. 315-18.

73. H.J. Borchardt: J. Inorg. Nucl. Chem., 1960, vol. 12, pp. 252-54.

74. G.O. Piloyan, I.D. Rybachikov, and O.S. Novikov: Nature, 1966 , vol. 212, p. 1229.

75. H. Yinnon and D.R. Uhlmann: J. Non-cryst. Solids, 1983, vol. 54, pp. 253-75.

76. H.L. Friedman: J. Polym. Sci. C, 1964, vol. 6, pp. 183-95.

77. J.A. Augis and J.E. Bennett: J. Therm. Anal., 1978, vol. 13, pp 283-92.52.

78. M.D. Seo, C.B. Shi, H. Wang, J.W. Cho, and S.H. Kim: J. Non-cryst. Solids, 2015, vol. 412, pp. 58-65.

79. C.B. Shi, J. Li, J.W. Cho, F. Jiang, and I.H. Jung: Metall. Mater. Trans. B, 2015, vol. 46B, pp. 2110-20.

80. Z. Wang, Q. Shu, and K. Chou: Metall. Mater. Trans. B, 2013, vol. 44B, pp. 606-13.

81. T. Watanabe, H. Hashimoto, M. Hayashi, and K. Nagata: ISIJ Int., 2008, vol. 48, pp. 925-33.

82. S.Y. Choi, D.H. Lee, D.W. Shin, S.Y. Choi, J.W. Cho, and J.M. Park: J. Non-cryst. Solids, 2004, vols. 345-346, pp. 157-60.

83. Q. Shu, J.F. Klug, and Q. Li: ISIJ Int., 2019, vol. 59, pp. $1057-$ 63.

84. Q. Shu, Q. Li, S.L.S. Medeiros, and J.F. Klug: Metall. Mater. Trans. B, 2020, https://doi.org/10.1007/s11663-020-01838-4.

85. C. Yang, G. Wen, and P. Tang: Steel Res. Int., 2016, vol. 87, pp. $880-89$.

86. C. Orrling, A. Tilliander, Y. Kashiwaya, and A.W. Cramb: Proc. 82nd Steelmak. Conf., Warrendale, PA, 1999, pp. 417-24.
87. N. Kölbl, I. Marschall, and H. Harmuth: J. Mater. Sci., 2011, vol. 46, pp. 6248-54.

88. L. Zhou, H. Li, W. Wang, Z. Wu, J. Yu, and S. Xie: Metall. Mater. Trans. B, 2017, vol. 48B, pp. 2949-60.

89. B. Lu, K. Chen, W. Wang, and B. Jiang: Metall. Mater. Trans. B, 2014, vol. 45B, pp. 1496-1509.

90. L. Zhou, H. Li, W. Wang, and J. Chang: Metall. Mater. Trans. B, 2018, vol. 49B, pp. 3019-29.

91. L. Zhou, W. Wang, R. Liu, and B.G. Thomas: Metall. Mater. Trans. B, 2013, vol. 44B, pp. 1264-79.

92. L. Zhou, W. Wang, D. Huang, and J. Li: Metall. Mater. Trans. $B, 2012$, vol. 43B, pp. 925-36.

93. K.C. Mills: Short Course as Part of South African Pyrometallurgy, 211, pp. 1-49.

94. C. Orrling and A.W. Cram: Metall. Mater. Trans. B, 2000, vol. 31B, pp. 403-06.

95. J.Y. Baek, J.W. Cho, and S.H. Kim: Metall. Mater. Trans. B, 2016, vol. 47B, pp. 32-36.

96. S. Gu, G. Wen, Z. Ding, J. Guo, P. Tang, and Q. Liu: Metals, 2019, vol. 9, p. 193.

97. J.Y. Park, J.W. Ryu, and I. Sohn: Metall. Mater. Trans. B, 2014, vol. 45B, pp. 1186-91.

98. M. Hanao: ISIJ Int., 2013, vol. 53, pp. 648-54.

99. J.W. Cho and H. Shibata: J. Non-cryst. Solids, 2001, vol. 282, pp. $110-17$.

100. J. Li, F. Lai, W. Yao, L. Hu, and Q. Liu: CrystEngComm, 2020, vol. 22, pp. 2158-65.

101. S.S. Jung, G.H. Kim, and I. Sohn: Trans. Indian Inst. Met., 2013, vol. 66, pp. 577-85.

Publisher's Note Springer Nature remains neutral with regard to jurisdictional claims in published maps and institutional affiliations. 